\title{
VI. NATION UND FORTSCHRITT
}

Die Denkmallandschaft aller Hauptstädte spiegelte wie auch schon vor den 1870er Jahren den Umstand wider, daß eine grundsätzliche Bereitschaft nicht nur staatlicher, sondern auch städtischer oder privater Initiatoren bestand, die Nation als Träger und Motor von Modernisierungsleistungen zu feiern. Wirtschaftswachstum, technologischer und wissenschaftlicher Fortschritt wurden ihr zugerechnet, Errungenschaften der Medizin als Signum des Aufbruchs in eine rational-aufklärerische Zukunft gewertet. Um die kausale Zuordnung konkurrierte mit der Nation allerdings gelegentlich auch das Ideal einer internationalen Wissensgemeinschaft.

\section{Paris: Zwischen humanitärem Konsens und politisch-religiöser Kritik}

In Paris fanden seit Ende der 1880er Jahre mehrere Denkmalerrichtungen statt, die am modernistischen Zuschnitt des Nationsbilds zu feilen schienen, indem renommiertes Personal aus den Bereichen von (Natur)Wissenschaft und Medizin zu öffentlicher Ehre gelangte. Bisweilen provozierte eine historische Verortung des Personals im Kontext der Revolution von 1789 Distanzierungen der moderat-republikanischen Presse. Der republikanische Optimismus, mit dem Formen der materiell-ökonomischen oder humanitären Ressourcenmobilisierung als wünschenswertes Symptom der effizienten und moralischen Nation gehandelt wurden, blieb davon zwar einerseits unberührt; die Politisierung des nationalen Diskurses hingegen lie $B$ es nicht zu, vom historisch-politischen Zeitkolorit der Kultfiguren zu abstrahieren, und führte dazu, daß die Konsensformeln vor allem publizistisch mehrfach unterlaufen wurden.

$\mathrm{Zu}$ den nahezu klassischen Denkmalehrungen für renommierte Mediziner, die der Projektion der humanitären Nation ohne allzu eindringlichen programmatischen Aufwand Vorschub leisteten, zählte zunächst unbelastet von Dissensphänomenen das Monument für den Psychiater und Pathologen Philippe Pinel, das im Juli 1885 auf dem Square Marie-Curie im 13. Arrondissement vor dem Hospital Salpétrière, wo Pinel gewirkt hatte, gefeiert wurde ${ }^{1}$. Hier

Vgl. Le Petit Joumal, 15. Juli 1885, S. 1. Der Zeremonie wohnten vor allem Mitarbeiter der Anstalt, der Seinepräfekt und der Präsident des Conseil Municipal bei. Regierungsvertreter hingegen fehlten 
charakterisierte der Präsident der initiierenden Société médico-psychologique Pinels innovative psychiatrische Diagnostik als Fortschrittsleistung von nationaler Reichweite ${ }^{2}$, während sich vor allem die republikanische Presse entsprechende Lesarten zu eigen machte und dann etwa der Petit Journal zunächst ein dunkles Bild vom nachlässigen und menschenverachtenden Umgang mit psychisch Kranken zeichnete, vor dem es Pinel einmal mehr als »bienfaiteur de l'humanité«, "gloire scientifique pour la France et pour le monde entier" und schließlich krönend als "grand citoyen« und Vorbild seiner »patrie« apostrophierte ${ }^{3}$.

Durchaus funktionale Aspekte der nationalen Konnotierung traten demgegenüber etwa anläßlich der Aufstellung einer Statue für den Chirurgen Jules Péan Mitte Dezember 1909 auf dem Boulevard Port-Royal im 13. Arrondissement gegenüber der Rue de la Santé und dem von ihm gegründeten Krankenhaus auf. Hier wandten sich die Initiatoren unmittelbar an den eigens zum Fest erschienenen Staatspräsidenten Fallières, der so Gelegenheit erhielt, sich nun seinerseits als Förderer von Humanität und Caritas und ihrer Repräsentanten feiern zu lassen, die auf der »chère terre de France« beheimatet seien. Nicht nur die assoziative Kopplung von Nation und »humanité et fraternité sociale ${ }^{4}$, sondern die autoritätsstärkende Zuschreibung nationaler Verbindlichkeiten auf Amt und Person des Präsidenten stand hier im Mittelpunkt der offiziellen Inszenierung.

Konsensuale Verfahren öffentlicher Ehrung betrafen nicht nur Personal aus dem Bereich der Medizin, sondern auch der Naturwissenschaften, denen ihre Stifter je neu mit dem Credo der modernen Nation huldigten ${ }^{5}$. Charakteristisch

2 Vgl. Une statue à Pinel. 25. März 1878, AN F F $^{21} 4856$ Dossier: Monument à Philippe Pinel, 17 septembre 1877-31 août 1884, médecin und [An.,] Inauguration de la statue de Philippe Pinel sur la place de la Salpétrière, le 13 juillet 1885 , Paris, S. 7.

Le Petit Journal, 15. Juli 1885, S. 1; [An.,] Inauguration, ibid. S. 6. Ähnliche Argumentationsmuster tauchten 1898 im Rahmen der Inauguration eines Denkmals für den Mediziner Jean Charcot am Boulevard de l'Hôpital im 13. Arrondissement auf, vgl. [LE RAYMOND,] Inauguration du monument élevé à la mémoire du professeur J.-M. Charcot. Discours prononcé le 4 décembre 1898 (par M. Le R., Professeur de Clinique des maladies nerveuses), Paris 1898, S. 5, 7, 16f. Ähnliches galt für die Programmatik im Umfeld der Anfang Juli 1907 eingeweihten Stele für den Arzt Théophile Roussel an der Avenue Denfert-Rochereau nahe dem Observatorium. Vgl. Comité de Patronage, 13 décembre 1903, AN F ${ }^{21} 4856$ Dossier: Monument Théophile Roussel, 15 décembre 1903-27 décembre 1906.

5 So entstand im Juli 1887 ein Denkmal fuir Paul Broca auf dem Boulevard Saint-Germain, das die von ihm 1859 gegründete Société d'Anthropologie initiierte. Vgl. Extrait (...), 14. März 1884, AN F $F^{\text {lc }}$ I 169 Dossier: 14 mars-25 juillet 1884 , autorisation d'ériger un monument à Broca; Schreiben der Société an den Ministre de l'Intérieur vom 29. Juli 1880, AN F ${ }^{\text {lc }}$ I 168 Dossier: 29 juillet-19 août 1880 Décret autorisant l'érection par souscription d'un monument à Broca. Im Sommer 1898 konnte ein von der Société des Ingénieurs civils initiiertes Büstendenkmal für den Ingenieur Eugène Flachat an der gleichnamigen Straße im 17. Arrondissement eingeweiht werden. Vgl. Le Temps, 13. Juni 1898, S. 2. 
blieb dabei ein eher elitärer und zeremoniell äußerst bescheidener Festrahmen. So feierte man das Denkmal für den Chemiker Nicolas Leblanc vor dem Conservatoire des Arts et Métiers im zentralen 3. Arrondissement Ende Juni 1887 zunächst in der Bibliothek des Konservatoriums im exklusiven Kreis von Wissenschaftlem ${ }^{6}$. Den Charakter einer öffentlichen Veranstaltung nahm das Prozedere nur allmählich an, indem am Ende der Feier die Ehrengäste mit dem Handels- und Industrieminister Dautresme an der Spitze die Bibliothek verlieBen und sich zur Enthüllung vor das Denkmal im Hof begaben. Erst nach dem vollständigen Ende der Symbolhandlungen wurden die Tore des Conservatoire für ein bereits wartendes Publikum geöffnet. Angesichts der erheblichen $\mathrm{Zu}$ schauermengen bat das Komitee den Minister, seine Rede ein zweites Mal vor der Öffentlichkeit zu halten. Der Minister kam dem Wunsch nach, und bei dieser Gelegenheit wurde auch die Nationalhymne ein zweites Mal intoniert. Die Feier erschien hier eher als bühnenhaft-artifizielles Stück, während ihre Exklusivität nicht definitiv zurückgenommen, sondern am Ende demonstrativ wiederhergestellt wurde, indem sich die Ehrengäste am Ende erneut in die Bibliothek zurückzogen?

Die Elogen auf Leblancs historische Verdienste als sfondateur de l'industrie chimique ${ }^{8}$ reflektierten zugleich auch die Anfangsjahre der Ersten Republik: "La France, attaquée de toutes parts et mise au ban des nations, [était] privée de matières nécessaires à sa défense et à son industrie «". In einer historischen Phase, in der also die Unabhängigkeit des revolutionären Frankreich auf dem Spiel stand, schlug nun die Stunde Leblancs, dessen Methode zur Sodaherstellung unversehens zum Ausdruck von "patriotisme« und "génie de l'invention propre à notre race« geriet und die Krise Frankreichs ebenso zu meistern half, wie zahlreiche andere Erfindungen französischer Wissenschaftler ${ }^{10}$. Über den zur Kultfigur erkorenen Leblanc ließ sich mithin gleichermaßen der revolutionäre Ursprung wie die modernistische Prägung und schöpferischeffiziente Freisetzung der Nation thematisieren, die die republikanischen Stifter als historisch legitimiertes und bewährtes Leitbild auch der zeitgenössischen Dritten Republik anempfahlen. Vom Profit, den über Frankreich weit hinausgehend die ganze Welt von Leblancs Erfindung hatte, zeugte schließlich der Überzeugung der Stifter zufolge die Subskription, die sich zu mehr als der Hälfte aus internationalen Spendengeldern zusammensetzte ${ }^{11}$. Damit weitete

6 Vgl. dazu und zum folgenden [An.,] Statue de Nicolas Leblanc, Inventeur du procédé de fabrication de la soude extraite du sel marin. Souscription nationale. Compte rendu de la cérémonie de l'inauguration du 28 juin 1887 , Colummiers 1887, S. 5 f.

7 Vgl. ibid. S. 27.

8 Vgl. [An.,] Statue de Nicolas Leblanc, S. 8.

9 Ibid. S. 9.

10 Vgl. ibid. S.10 und 12.

"Vgl. ibid. S. 20. 
sich das Leistungsprofil der Nation zum transnationalen Fortschrittsmotor und erschien die Kultfigur als universaler Sympathieträger.

Vor diesem Hintergrund visierte der Direktor des Conservatoire Laussedat gleich ein ganzes Ensemble von Statuen an, das er als »Panthéon des inventeurs ${ }^{12}$ entstehen sehen wollte, um die nationale Kanonisierung auf die Figurenkategorie von naturwissenschaftlich-technischen Forschern auszudehnen ${ }^{13}$. Auch bei vergleichbaren Denkmalunternehmungen schwang erneut die These mit, daß die Nation nicht nur von der Bereicherung ihrer intellektuellmoralischen, politischen oder militärischen Verfaßtheit, sondern auch von den erfinderischen Eingriffen in ihre materiellen Bedingungen durch die Protagonisten des Fortschritts profitierte, die gleichermaßen zur "gloire de la France» beitrugen.

$\mathrm{Da} \beta$ mit dem wissenschaftlichen Personal keineswegs automatisch Konsens jenseits tages- und parteipolitischer Differenzen zugunsten nationaler Topoi abrufbar war, zeichnete sich indessen ebenso ab. So ließ sich etwa Le Temps auf den Tenor der Reden ein, verband die historische Verortung in der revolutionären Phase des 18. Jahrhunderts allerdings weniger mit Umbruchsemphase als mit deutlichen Distanzierungen vom revolutionären Radikalismus. Leblancs Gründung einer ersten Fabrik zur künstlichen Sodaherstellung in SaintDenis sprach der Temps daher mit dem Hinweis darauf an, daß seinerzeit die Intervention des Comité du salut public Leblanc durch Enteignung um die Früchte seines Erfolgs gebracht hatte ${ }^{14}$, so daß er zwar 1801 seinen Besitz wiedererlangte, aber lange auf die vollständige »récompense nationale« warten mußte. Die zwanghafte Zerschlagung von Besitz und seine Okkupation als Nationalgut, mit der die Revolutionäre die Sanierung des maroden Wirtschaftssystems unternommen hatten, bedachte Le Temps mit nachträglicher Verachtung und trug dafür Sorge, daß sich wissenschaftliches und revolutionäres Pathos nicht ungehörig mischten ${ }^{15}$.

Die zunächst konsensfähige Selbstvergewisserung als effizient-fortschrittliche Nation konnte unter dem Eindruck politischer Stigmatisierungen, mit denen das national konnotierte Personal belegt wurde, Dissens nach sich

12 Ibid. S. 26; Le Temps, 29. Juni 1887, S. 2.

13 Vgl. auch die ähnliche Rede Laussedats anläßlich der Einweihung des Denkmals für Denis Papin im Hof des Conservatoire am 16. Januar 1887, in: Albert CAHEN, Société des anciens élèves des Ecoles Nationales des Arts et Métiers. Note sur Denis Papin à l'occasion de l'inauguration de sa statue au conservatorie national des Arts et Métiers, Paris 1887, S. 11-13, 17 .

14 Vgl. Le Temps, 29. Juni 1887, S. 2.

15 Vgl. auch Le Petit Joumal, 12. Juli 1885, S. 1. Vgl. eine ähnliche Argumentation im Umfeld des Denkmals für Claude Chappe im Sommer 1893, den man für seine Verdienste um die Perfektionierung des Fernmeldewesens ehrte. Vgl. Brief des Komiteevorsitzenden Boussac an den Innenminister am 18. Februar 1892, AN F ${ }^{\text {le }}$ I 169 Dossier: 18 février 1892-11 mars 1893 Erection de la statue de Claude Chappe. 
ziehen. Besonders eindrücklich machte sich dieser Effekt anläßlich der Feier eines auf Initiative der Société de biologie für den Physiologen Claude Bernard Anfang Februar 1886 auf dem Square Marcelin-Berthelot im 5. Arrondissement errichteten Denkmals bemerkbar. Während die republikanische Regierung mit ihrem Unterrichtsminister Goblet neben zahlreichen hochrangigen Forscherpersönlichkeiten aus dem Komitee das Unternehmen in nationaler Absicht begrüßte ${ }^{16}$, blieb der erzkonservative und katholische Univers skeptisch. Bernards Verdienst um die "patrie« erkannte man hier an, während nun Denkmalstifter und Festredner mehr als die Figur Anlaß zu Kritik gaben: "pour Claude Bernard, la méthode scientifique (...) étai[t] bien loin d'être po$\mathrm{s}$ [ée] en antagonisme avec la croyance en Dieu et en faveur de l'esprit de secte par lequel s'est signalé Paul Bert« ${ }^{17}$. Daß der Vorsitzende des Denkmalkomitees Bert und andere Redner bezichtigt wurden, »intentions blasphématoires ${ }^{18}$ zum Ausdruck gebracht zu haben, mußte angesichts der eher unspektakulären Reden überzogen wirken. Gleichwohl manifestierte sich in diesem Vorwurf das Ressentiment des konservativ-katholischen Lagers dagegen, nun auch die Erinnerung der großen Wissenschaftler von den Republikanern verwaltet zu sehen, die der Univers einer gezielt atheistischen Traditionsbildung auch gegen das Credo der eigentlich Geehrten verdächtigte.

$\mathrm{Da} ß$ schließlich Konsens im Blick auf den Kult dezidiert wissenschaftlichen Personals nicht nur von der politischen Rechten, sondern auch aus linksrepublikanischer Sicht verweigert werden konnte, dokumentierte auch die gegen das Bernard-Denkmal längst laut gewordene linke Kritik. In diesem Sinne hatte sich noch zu Beginn der Initiative im März 1878 Conseiller Henricy im Pariser Stadtrat mit der Bemerkung zu Wort gemeldet, er sei in seiner Eigenschaft als »républicain« und »libre penseur« nicht bereit, das Projekt mitzutragen, weil Bernard immerhin »ancien sénateur de l'Empire« gewesen sei ${ }^{19}$. Henricys Einspruch bezog sich mithin ebenso auf die gebrochene politische Biographie des Geehrten, die Affinitäten zu Empire und Illiberalismus argwöhnen ließ. Die Mehrheit des Conseil setzte sich zwar über dergleichen Bedenken hinweg. Die Konsensfloskel wirkte aber angestrengt und vordergründig, weil über die Assoziationen, die die Figur für die Nation nahelegte, nicht wirklich Einhelligkeit zu erzielen war.

$\mathrm{Da}$ biographische Brüche potentiellen Kultfiguren insbesondere von der politischen Linken Kritik eintrugen, trat erneut anläßlich einer Ende Juni 1889 erfolgten Denkmaleinweihung für den Astronomen Urbain Le Verrier vor der Pariser Sternwarte (Observatoire) zutage. Während der Ehrenpräsident der

${ }^{16}$ Vgl. La Petite République, 9. Februar 1886, S. 1, 2.

17 L'Univers, 10. Februar 1886, S. 2.

18 Ibid.

19 Vgl. Participation de la ville (..), séance du 21 mars 1878, in: CMPV, Année 1878, S. 207. 
Association scientifique de France für das Monument warb, indem er behauptete, daß Le Verrier nicht nur die "science française« an sich bereichert, sondern ihr auch Weltgeltung verschafft habe ${ }^{20}$, zögerte der Conseil Municipal, als es um die Zuerkennung eines Standortes ging. Gegen das Projekt wurde eingewandt, daß zuvor Le Verriers Vorgänger am Observatorium, François Arago, ein öffentliches Denkmal verdiene, der sich nicht nur wissenschaftlich als Astronom, sondern vor allem auch als Mitbegründer der Zweiten Republik profiliert habe. Für Le Verrier müsse eine Aufstellung im Innenhof des Observatoriums genügen, die dann derjenigen etwa Larreys im Hof des Val-deGrâce oder Gutenbergs im Innenhof der Imprimerie nationale entspreche ${ }^{21}$. Die Verweigerung kaschierte den politischen Vorbehalt gegenüber Le Verrier, der, vom Empire hofiert, 1853 auf Kosten Aragos an die Spitze des Observatoriums aufgerückt war $^{22}$.

Noch in den Festreden Ende Juni 1889 hinterließ der Vorbehalt Spuren ${ }^{23}$, indem die Denkmalstifter sich nun zu betonen bemühten, daß Le Verrier während des Empire nicht nur den Vorsitz des Observatoire erlangt und als Senator gewirkt, sondern auch seinen beruflichen Abstieg erlebt hatte und erst unter der Republik seine Karriere fortzusetzen vermochte ${ }^{24}$. So wurde versucht, Le Verrier vom politisch nicht opportunen Kontext des Empire zu isolieren und der Dritten Republik zuzuordnen.

Konsenssuche auf dem Hintergrund bereits bekannter Kritikmuster signalisierten auch die Worte des Sekretärs der Académie des sciences Bertrand, der sich um den Nachweis religiöser Loyalitäten mühte: Le Verrier habe sich durch seine Forschertätigkeit nie zum blasphemischen Triumph verleiten lassen, sondern sei ein gottesfürchtiger Mann geblieben ${ }^{25}$. Bertrand wies hier der Fortschritts- und Aufklärungsemphase die metaphysischen Grenzen und empfahl Le Verrier auch dem Kult nicht nur durch die laizistische, sondern auch durch die religiös affizierte Nation.

Der Direktor des Observatoire und Konteradmiral Mouchez schließlich nahm die nationale Zuordnung der Figur noch einmal stellvertretend für die Kategorie des fortschrittlichen Kultpersonals vor:

Vgl. Allocution de M. Dumas, séance d'ouverture du 26 janvier 1879, Conférence à la Sorbonne, in: Souscription pour élever un monument à la mémoire de Le Verrier, o. J., S. 1, 4-5, 7, AN F ${ }^{1 \mathrm{c}}$ I 168 Dossier: 8 mars 1878-avril 1879. Projet d'érection d'une statue à la mémoire de l'astronome Leverrier [up].

21 Vgl. Rejet d'une demande, séance du 11 mars 1879, in: CMPV, Année 1879, $1^{\text {er }}$ sem., S. $248 \mathrm{f}$.

22 Vgl. CARON, Frankreich im Zeitalter des Imperialismus, S. 133.

23 Vgl. Le Temps, 28. Juni 1889, S. 4.

${ }^{24}$ Vgl. [An.,] Discours prononcès à l'occasion de la statue de Le Verrier à l'observatoire de Paris, le jeudi 27 juin 1889, Paris 1889 (Institut de France. Académie des Sciences), S. 6.

25 Vgl. ibid. S. 10f.; Le Temps, 28. Juni 1889, S. 4. 
Si l'on rend à juste titre tant d'honneur au soldat mort en combattant, quoi ne doit-on pas aussi au savant qui (...) laisse en outre comme héritage à sa patrie la gloire de ses découvertes, et à l'humanité un nouveau progrès dans la connaissance de l'Univers ${ }^{26}$.

Das Verdienst des Wissenschaftlers um die Nation erschöpfte sich nicht im tapferen Opfertod als einer eher mystischen Hinterlassenschaft, sondern bestand in der Eröffnung zukunftsträchtiger, über die Nation hinaus gleich der ganzen Menschheit zuträglicher Fortschrittsperspektiven ${ }^{27}$.

Spätestens bis zur Jahrhundertwende war die Kultpraxis auch zugunsten naturwissenschaftlichen Personals längst etabliert und mußte nicht immer im Vorfeld gleichsam erst konfliktbereinigt werden. Davon zeugte im Sommer 1900 die Denkmalfeier für den Chemiker Antoine Laurent de Lavoisier, der mit einer Statue auf der Place de la Madeleine im 8. Arrondissement gegenüber seinem ehemaligen Wohnsitz im Beisein des Seine- und des Polizeipräfekten sowie zahlreicher Mitglieder der Académie des sciences in offizieller Amtstracht und sonstiger Chemiker sowie mehrerer Abordnungen ausländischer wissenschaftlicher Gesellschaften geehrt wurde ${ }^{28}$. Hier feierte man Lavoisier als Repräsentanten der großen »découvertes scientifiques qui ont transformé à la fois les connaissances générales (...), enrichi l'industrie (...) et concouru par là même à l'affranchissement intellectuel, moral et matériel des peuples $\ll^{29}$. Um dieses globalen wissenschaftlichen wie humanitären Verdienstes willen ordnete man Lavoisier in eine Reihe mit Galilei, Newton und Leibniz und also in eine internationale Phalanx von Neuerem ein, die vom wrapprochement des (...) nations« zeugten, weil sie ein gemeinsames Fortschrittsziel erstrebten, ohne daß einem von ihnen ein smonopole« zukam. Das dokumentierte auch die internationale Subskription, die die Wissenschaftler zweier Hemisphären vereinte, insofern sich an ihr neben Franzosen auch Deutsche, Engländer, Italiener, Russen und Amerikaner beteiligten ${ }^{30}$. Eine französische Führungsposition im Unternehmen blieb angedeutet, gegenüber dem assoziierten Bild einer harmonischen internationalen Wissenschaftsgemeinschaft gleichwohl nachrangig.

Die öffentliche Monumentalisierung der Forscherfigur in nationaler Absicht funktionierte damit nicht nur weithin inklusiv und ohne Feindbildassoziationen, sie verband sich sogar mit dem Anspruch moralischer Überlegenheit, sofern sie anders als die Monumente für die whommes de guerre« und die "hommes d'État«, die bisweilen »sans aucun profit durable pour la nation«

Vgl. [An.,] Discours prononcé à l'inauguration de la statue de Le Verrier, S. 12 [E. MOUCHEZ].

gl. Le Temps, 28. Juli 1900, S. 3

$29 \mathrm{Vgl}$. [An.,] Inauguration du monument érigé á Lavoisier par une souscription internationale, sous le patronage de l'Académie des Sciences, le 27 juillet 1900, Paris 1900, S. 4.

${ }^{30} \mathrm{Vgl}$. ibid 
blieben, nun die fortschreitende Aufgeklärtheit der Nation dokumentierten, der der Verdienst um die "race humaine« mehr galt als die Taten jener vordem geehrten »êtres de sang et d'intrigue $\aleph^{31}$.

Auf dem Höhepunkt der Denkmalstiftungen für renommierte Forscher kam schlieBlich auch die Statue für Louis Pasteur Mitte Juli 1904 auf der Place de Breteuil an der Grenze vom 7. zum 15. Arrondissement im Westen der Stadt nahe dem Invalidendom zustande. Selbst Staatspräsident Loubet war neben den Präsidenten der Kammer und des Senats, mehreren Parlamentsmitgliedern und Angehörigen des diplomatischen Corps sowie zahlreichen Vertretern des internationalen Wissenschaftbetriebs erschienen. Auch hier kündigte die Symbolik bereits eine transnationale Sinnstiftungsambition an, indem das Denkmal mit Blumen und Kränzen in den Farben aller an der Finanzierung und der Feier der Statue beteiligten Nationen geschmückt war $^{32}$. Ebenso endete die Zeremonie nach einer langen Reihe von Festansprachen mit dem Verlesen internationaler Adressen, die Zustimmung zum Denkmal auch außerhalb Frankreichs symbolträchtig bekunden sollten. Unter anderem stilisierte der Präsident des Conseil Municipal Desplas Pasteur in mythischer Aufladung zum Prometheus, der Licht in die bis dahin obskure Wissenschaft der Biologie gebracht und so der französischen Nation wie auch einer globalen »humanité« gedient habe, auf der Krankheiten wie der Bann einer mittelalterlich-urwüchsigen Gewalt lasteten. Pasteur rettete der Metapher zufolge Nation und Menschheit vor Verfall und Siechtum in Gestalt von Tuberkulose und Cholera. Darüber hinaus hinterließ er traditionswirksam eine Schülerschaft, die sein Werk fortsetzte und komplettierte ${ }^{33}$. Der Präsident der Académie des Sciences würdigte, daB Pasteur »après nos désastres, (...) faisait appel à la science pour le relèvement du pays $\aleph^{34}$. Der medizinische Fortschritt geriet damit auch zum zentralen Vehikel nationaler Selbsterneuerung nach der politischen und moralischen Niederlage von 1870/71 und zur Regeneration der modernen, widerstandsfähigen Nation $^{35}$.

31 Vgl. ibid. S. 5; Le Gaulois, 28. Juli 1900, S. 3. Die Enthüllung eines Doppeldenkmals für die beiden Chemiker Joseph Caventou und Pierre Pelletier wenige Tage später im 5. Arrondissement zeigte eher Verschleißmomente. Vgl. u.a. Le Temps, 8. August 1900, S. 3. Programmatische Redundanz bestimmte auch die Reden anläßlich der Inauguration einer Statue für den Naturforscher und Zoologen Jean-Baptiste Lamarck im Juni 1909 im Jardin des Plantes des 5. Arrondissement. Vgl. Musée National d'Histoire Naturelle [undatierter Subskriptionsaufruf], AN F 4856 Dossier: Monument Lamarck, par Fagel, 29 avril 1907-9 avril 1910; Le Petit Joumal, 14. Juni 1909, S. 3; Le Gaulois, 13. Juni 1909, S. 1.

32 Vgl. Le Temps, 17. Juli 1904, supplément, S. 1; Le Gaulois, 17. Juli 1904, S. 2.

33 Le Temps, 17. Juli 1904, supplément, S. 1.

34 Ibid. Vgl. auch [An.,] Discours prononcé à l'inauguration du monument élevé à la mémoire de Pasteur à Paris, le samedi, 16 juillet 1904, Paris 1904 (Institut de France), S. 17.

35 Vgl. Le Temps, ibid. 
Während dem Projekt allenthalben öffentlicher Beifall sicher war ${ }^{36}$, mahnte nur im Gaulois François Coppée die Würdigung gänzlich anderer Kultkriterien an, als sie von den Rednern ins Feld gefuhrt worden waren, indem er darauf abhob, daß Pasteur vor allem »en chrétien« gelebt und seinen Katholizismus nie verleugnet habe ${ }^{37}$. Demgegenüber attackierte Coppée eine Republik, die der Nation rigiden Laizismus verordnete, während er statt dessen die Verschmelzung von "patrie« und »christianisme« in einem christlich-katholischen Nationalismus propagierte ${ }^{38}$. Die Denkmalerrichtung atmete damit zunächst weniger im Rahmen ihrer öffentlichen Inszenierung, durchaus allerdings im Zuge der publizistischen Rezeption, den Geist wiederaufgeflammter Grundsatzkonflikte zwischen dem inzwischen militanten Antiklerikalismus der radikalen Republik des frühen 20. Jahrhunderts und einem ungeachtet seiner mehrheitlichen Ächtung im nationalen Diskurs nach wie vor präsenten Katholizismus, der sich offensiv gegen die verordnete Exklusion aus dem nationalen Verband zur Wehr setzte.

Initiatoren von Denkmalprojekten für wissenschaftliches Personal konnten allerdings von der Konjunktur zugunsten dieser Monumentkategorie nicht profitieren, wenn sie die nationale Entgrenzungsidee im sozialistischinternationalistischen Sinne vornahmen. Davon zeugten die Projekte, die Conseiller Vorbe zweimal erfolglos im Conseil Municipal dringlich machte. Dies galt zunächst für ein im Oktober 1895 thematisiertes Denkmalprojekt für Isaac Newton ${ }^{39}$ und schließlich erneut im November 1898 und März 1900 für ein öffentliches Denkmal zum Gedenken an Galileo Galilei ${ }^{40}$. In beiden Fällen legte Vorbe fulminante Plädoyers für die zivilisatorischen Errungenschaften vor, die die Welt beiden Wissenschaftlern verdankte und die Frankreich mit seinem besonderen Interesse an der véducation sociale $\ll^{41}$ im Monument $\mathrm{zu}$ bewahren berufen schien. Im Falle des Galileo-Projekts weitete Vorbe seine Projektion gar zugunsten eines groß angelegten Konzepts monumentaler Vernetzung der Kapitalen der Welt durch die Errichtung öffentlicher Denkmäler für die Repräsentanten der Menschheit, die eine zivilisatorisch begründete Harmonie zwischen den unterschiedlichen "patries« würden illustrieren kön-

Vgl. Le Temps, 17. Juli 1904, supplément, S. 1; Le Siècle, 17. Juli 1904, S. 1 [Gustave KAHN].

37 Vgl. Le Gaulois, 16. Juli 1904, S. 1 [François COPPÉE].

38 Ibid.

39 Vgl. Adoption d'une proposition de MM. Pierre Baudin et Vorbe relative à l'érection d'une statue à Isaac Newton, séance du 28 octobre 1895, in: CMPV, Année 1895, $2^{c}$ sem., S. 444-454.

40 Vgl. Renvoi à la $4^{\mathrm{e}}$ Commission d'une proposition de $\mathrm{M}$. Vorbe, séance du 25 novembre 1898, in: ibid. Année 1898, $2^{\complement}$ sem., S. 770-771; Érection d'une statue à Galilée, séance du 23 Mars 1900, in: ibid. Année 1900, $1^{\text {er }}$ sem., S. 260-280.

41 Érection d'une statue à Galilée, ibid. S. 272. 
$\mathrm{nen}^{42}$. Er regte an, regelmäßige »fêtes populaires« abzuhalten, die die globale Symbolharmonie durch eine internationale Festkultur ergänzen sollten, und dabei die "travailleurs《 an zentraler Stelle beteiligten ${ }^{43}$. Vorbes sozialistische Vision rückte damit nicht nur provokant die universale "société humaine« an die Stelle der dann sekundären Nation, sie implizierte auch Kritik an der mangelnden Inklusion des »peuple« in die zeitgenössische Festpraxis. Außerhalb des politisch linksorientierten Conseil konnten die von Vorbe vorgetragenen und von zahlreichen Conseillers unterstützten Vorlagen allerdings kein Gehör finden.

\section{Berlin: Transnationale Weitung, kompetitive Verengung und Loyalitätskonkurrenz}

Gemessen an den Pariser Projekten nahmen sich die Berliner Denkmalinitiativen, die für wissenschaftsnahes Personal zustandekamen, deutlich heterogener aus. In den frühen 1880er Jahren zeugte die Feier der Humboldt-Statuen davon, daß neben dem Aspekt wissenschaftlicher Fortschrittlichkeit die Reformassoziation bedeutsam blieb, während erst ein Mediziner-Denkmal 1890 wissenschaftlichen Fortschritt und Nation konstitutiv verknüpfte. Bis Ende der 1890er Jahre dominierte vor allem mit den Krupp- und Siemens-Denkmälern rasch ein drastisch kompetitiver Ton das Deutungsverfahren. Daß die transnationale Deutungsoption Anknüpfungsmöglichkeiten für die politische Linke bieten konnte, deutete sich schon zu Beginn der 1890er Jahre im singulären Fall des Senefelder-Denkmals an.

Ende Mai 1883 wurden zunächst die Denkmäler für Alexander und Wilhelm von Humboldt beiderseits des Portals der Universität Unter den Linden auf einem aufwendig nicht nur in den preußischen, sondern auch in den »deutschen Landesfarben « geschmückten Festplatz eingeweiht ${ }^{44}$. Das Staatsministe-

Vgl. ibid. S. 274: „Il faudrait que des monuments ayant le même caractère fussent élevés sur les places publiques de toutes les capitales des contrées de la République occidentale. Les monuments seraient comme les précurseurs souhaités du drapeau de l'Humanité qui portera dans ses plis la prospérité des patries, la paix et la fraternité des peuples."

Vgl. ibid.: "Il faut y introduire les travailleurs. Dans la commémoration des événements mémorables de notre histoire et de nos illustrations, de nos gloires nationales, le peuple est trop passif. (...) les grands hommes sont trop isolés. Il est indispensable (...) de rappeler les liens tangibles et indestructibles qui les unissent aux travailleurs manuels."

44 Vgl. zum Folgenden VZ, 28. Mai 1883 (A.), S. 2; NZ, 28. Mai 1883 (A.), S. 2; NPKZ, 29. Mai 1883, S. 2-3. Vgl. knapp auch Klaus-Dietrich GANDERT, Vom Prinzenpalais zur Humboldt-Universität. Die historische Entwicklung des Universitätsgebäudes in Berlin mit seinen Gartenanlagen und Denkmälern, Berlin (Ost) 1985, S. 163-174. 
rium war vollständig erschienen, daneben zahlreiche Mitglieder des Abgeordnetenhauses und des Reichstages, die meisten der damals akkreditierten Botschafter, städtische Vertreter sowie Studenten aller Fakultäten und Vertreter der Universität und der Präsident des evangelischen Oberkirchenrates. Obgleich auch Generale und sonstige Offiziere anwesend waren und die Vertreter der Universität unter den Klängen eines Marsches den Festplatz betraten, blieb die Szene zivil bestimmt und schloß mit der »Nationalhymne ${ }^{45}$. Der Kaiser, zum Prozedere zunächst erkennbar auf Distanz geblieben, indem er sich nicht eigens auf dem Festplatz eingefunden, sondern die Zeremonie vom Balkon des Königlichen Palais aus verfolgt hatte, beehrte das Fest dann doch noch mit persönlicher Präsenz, als er sich am Ende, begleitet von den Prinzen und weiterem Personal, auf den Platz begab ${ }^{46}$.

Kultusminister Gustav von Goßler identifizierte Wilhelm von Humboldt in seiner Ansprache als gleichermaßen »König und Vaterland" ergebener "treuer« Diener, »Geistes-Heros« und »Bürger« und evozierte als Quintessenz dieser unterschiedlichen Rollen Humboldts Bedeutung für die preußischen Bildungsreformen. Demnach arbeitete Humboldt am »Wiederaufbau Preußens von Innen heraus, [an der] intellectuelle[n] und moralische[n] Führung des gesammten Deutschland ${ }^{47}$ mit und hatte insofern Teil am Gründungsmythos der preußischen Nationalgeschichte, als er sich an der Etablierung Berlins als "geistige[m] Mittelpunkt» gleichermaßen Preußens und des Reichs beteiligte. Humboldts Rolle als Sprachforscher blieb demgegenüber marginaler, ließ ihn vage als Erkunder des Wesens der Nation erscheinen, der zum »Verständnis des deutschen Volks « in besonderer Weise beigetragen habe ${ }^{48}$. Die Rede des Liberalen Rudolf Virchow zum Denkmal Alexander von Humboldts, der in den 1820er Jahren durch seine Geographie-Vorlesungen an der Berliner Universität und später durch die Publikation von populärwissenschaftlichen Reiseberichten über Mittel- und Nordostamerika öffentliches Renommee weit über enge Wissenschaftszirkel hinaus gewonnen hatte, zielte noch unvermittelter auf die Stilisierung zum »Nationaldenkmal $\ll$ ab. Dessen Qualität erwies sich Virchow zufolge bereits in der Subskription, an der sich zahlreiche Deutsche auch außerhalb des Landes beteiligt hätten. Sie dokumentierte schließlich auch die Bereitschaft des Königs, dem »bürgerlichen Verdienst diese triumphale Straße seiner Hauptstadt $z u$ öffnen $\aleph^{49}$ und die Errichtung des HumboldtDenkmals in der Nähe des machtstaatlichen Repräsentationsforums um das

Vgl. Germania, 29. Mai 1883, S. 3; Berliner Tageblatt, 28. Mai 1883 (A.), LAB A Rep. 000-02-01 Nr. 1634, Bl. 92.

Vgl. u.a.VZ, 28. Mai 1883 (A.), S. 2; ibid. 29. Mai 1883 (1. B.), S. 2.

47

VZ, 28. Mai 1883 (B.), S. 2; NZ, 29. Mai 1883 (1. Bbl.), S. 2; NPKZ, 30. Mai 1883

(1. B.), S. 1.

$48 \mathrm{Vgl}$. ibid.

49 Vgl. ibid. 
Schloß und die Lindenallee zuzulassen. Überhaupt zeugte Virchows Worten zufolge das öffentliche Denkmalterrain der Metropole längst von der »nationalen Wiedergeburt unseres Volkes« und einer Teleologie der nationalen Geschichte:

Wer jetzt durch unsere Straßen wandert, der wird es empfinden, daß Goethe und Schiller, Stein und die Humboldts, Blücher und Scharnhorst nicht zufällig nebeneinander gelebt haben, daß vielmehr ein erkennbarer Zusammenhang ihre Entwicklung beherrscht und ihr Wirken zu einem einheitlichen Endziel zuammengefügt hat ${ }^{50}$.

Damit bildete die öffentliche Denkmallandschaft der Kapitale die Bestimmung der Nation zur Einheit aus der Vielheit ihrer - freilich ausschließlich preuBisch-militärischen wie zivilen historischen Leistungsträger ab.

Zugleich leistete sich Virchow eine provokante Aussparung, indem er diese Funktion des nationalen Kultpersonals ganz ohne den Rekurs auf die inzwischen schon errichteten Monarchendenkmäler erfüllt sah. Sofern er mit Alexander von Humboldt den »teuren Freund bürgerlicher Freiheit« als weiteres Versatzstück zum Denkmalensemble feierte, ordnete er die Statue weniger dem monarchischen Machtstaat als der Errungenschaft von politischer Partizipation und freiheitlicher Moral im Sinne eines bürgerlich-liberalen Wertekodex zu. Daneben diente die Reminiszenz an den »Nationalökonom《, »Bergmann«, »Astronom《, »Physiker«, »Chemiker«, »Geolog«, »Anatom und Experimentator ${ }^{51}$ dem Nachweis modernen und vielseitigen Forschertums, von dem wiederum die progressive, mindestens wissenschaftlich emanzipierte $\mathrm{Na}$ tion profitierte.

Damit nahmen sich die Reden zugleich stark elliptisch aus. Sie thematisierten weder den Umstand, daß Wilhelm von Humboldt nach seiner Berufung ins Kultusministerium 1808 nur knapp eineinhalb Jahre gewirkt hatte, bevor er aus Sorge um entscheidungspolitische Einengung durch den Staatsrat um seine Entlassung bat. Unerwähnt blieb auch, daß Humboldt sich nicht nur als Vertreter eines von Hardenberg differierenden liberalen Verfassungsgedankens für Preußen, sondern 1819 auch als scharfer Opponent der reaktionären Karlsbader Beschlüsse zu erkennen gegeben hatte ${ }^{52}$. Demgegenüber überwog das Bestreben, im denkmaltopographischen Arrangement von 1883 den Humboldtschen Reformgeist im Gleichklang mit dem kaiserlichen Willen, mithin ein konsensfähiges Bekenntnis zur nationalen Innovation zu erkennen.

Von interpretatorischen Auslassungen war die Deutung der Alexander von Humboldt-Statue ebenso betroffen, da zugunsten des Wissenschaftslobs hier

so Ibid

51 Ibid.

52 Vgl. so hingegen bereits zeitgenössisch [Adolf SCHULZE], Die Denkmäler der Freiherren von Humboldt im Vorgarten der Königlichen Universität, Berlin 1883, S. 14. Vgl. Joachim WOHLLEBEN, Wilhelm von Humboldt, in: ERBE (Hg.), Berlinische Lebensbilder, Bd. 4, S. 1-20, hier S. 1-15. 
nun jene eminent politische Rolle ausgeklammert blieb, die er etwa als Fürsprecher des liberalen Professors Kuno Fischer gespielt hatte, dem der konservative Kultusminister von Raumer 1855 die Venia Legendi aberkannte, bevor Humboldts Einspruch die Intervention Friedrich Wilhelms IV. nach sich gezogen hatte ${ }^{53}$. Die liberal-antireaktionäre politische Grundhaltung der HumboldtBrüder, die zur Kritik an den Defiziten politischer Beteiligungschancen noch im Kaiserreich hätte anleiten können, wurde insofern seitens der Denkmalstifter nicht hervorgehoben.

Stärker als in den Einweihungsreden klangen die bürgerlich-liberalen Deutungen der beiden Humboldt-Denkmäler im Rahmen des vom Kuratorium der Humboldt-Akademie und dem Ausschuß eines Wissenschaftlichen Zentralvereins initiierten Festaktes an, der am gleichen Abend im Kreise des Kultusministers, Oberbürgermeisters und zahlreicher hoher Beamter im Rathaus stattfand $^{54}$. Vor allem Wilhelm von Humboldt wurde hier als "Muster des Strebens nach Selbstbildung durch Concentration im Denken und im Charakter« und als Mahner zur "Selbsthilfe und Selbstverantwortlichkeit aus dem Prinzipe der Sittlichkeit heraus«, sein Bruder Alexander als Exempel des wissenschaftlichen "gemeinsamen Arbeitens der verschiedenen Nationen " geehrt $^{55}$. Damit standen in den stärker noch als die Denkmaleinweihung einer bürgerlichen $\mathrm{Zu}$ hörerschaft vorbehaltenen Reden emanzipatorische Teilhabe und internationale Öffnung um des wissenschaftlichen Fortschritts willen im Zentrum der Deutungsmuster, in denen zugleich endgültig jeder Rekurs auf den monarchischen Machtstaat fehlte.

Das publizistische Echo auf die Denkmalfeier blieb geteilt ${ }^{56}$. Der Wissenschaftler und Mitinitiator Emil Du Bois-Reymond unterstrich noch einmal ausführlich den Fortschrittsgedanken, der sich vor allem mit Alexander von Humboldt verband und sah in ihm den Überwinder einer mystifizierenden Naturphilosophie zugunsten wissenschaftlich luzider Experimentalforschung, von der ebenso »Preußen « und »Deutschland « wie die »Welt« profitierten ${ }^{57}$. Nicht zuletzt bescheinigte er dem Geehrten auch in Deutschland neben den traditionellen »Geistes«- die »Naturwissenschaften« mit gleichem Prestige auszustat$\operatorname{ten}^{58}$.

Die liberale Presse neigte demgegenüber zu einer deutlichen Politisierung der Fortschrittsmetapher. Etwa setzte sich die National-Zeitung über die kon-

53 Vgl. WEHLER, Gesellschaftsgeschichte, Bd. 3, S. 417f.

${ }^{54} \mathrm{Vgl}$. VZ, 29. Mai 1883 (1. B.), S. 2; NZ (1. Bbl.), 29. Mai 1883, S. 2.

55 Vgl. auch Wilhelm FOERSTER, Alexander von Humboldt. Eine Gedächtnisrede zur Feier der Denkmalenthüllung am 28. Mai 1883 im Festsaale des Rathauses zu Berlin, Berlin 1883, hier S. 24.

56 Vgl. sehr zurückhaltend NPKZ, 29. Mai 1883, S. 2-3; ibid. 30. Mai 1883, S. 1; Germania, 29. Mai 1883, S. 3.

57 Vgl. DU BOIS-REYMOND, Die Humboldt-Denkmäler, S. 95 und 101.

58 Vgl. ibid. 102. Vgl. auch DAUM, Wissenschaftspopularisierung, S. 161-167. 
sensheischenden Auslassungen der Festreden hinweg ${ }^{59}$. Beide HumboldtStatuen erschienen zwar in einer Reihe mit denjenigen der Generale der Befreiungskriege, die für die Aktivierung der »Kräfte eines selbstbewußten Volkes ${ }^{60}{ }^{6}$ standen. Sie verbürgten aber neben dem militärischen auch den zivilisatorischen Charakter der Nation, die sich nicht nur gegenüber einem äußeren Feind, sondern auch nach innen zu emanzipieren hatte. Die National-Zeitung verhehlte dabei nicht ihre Überzeugung, daß nurmehr eine längst überfällige Korrektur der national intendierten Monumentalsymbolik in der Hauptstadt geleistet worden war:

Vergebens suchte bis zum heutigen Tage der Blick, welcher vom Brandenburger Thor bis zum alten Hohenzollernschlosse diese Straße der geschichtlichen Erinnerungen hinunterschweift, ein Denkmal, das aus der Zeit der großen Erhebung vom Anfang des Jahrhunderts nicht blos von kriegerischen Thaten redete. Spät und seitab, auf einem Marktplatze [i.e. auf dem Dönhoffplatz, H.R.], ist Stein's Standbild errichtet worden; Hardenbergs Verdienste um Preußen sind bis auf diese Stunde durch kein Monument geehrt worden. Mit umso lebhafterer Befriedigung wird man fortan $\mathrm{zu}$ Wilhelm von Humboldt's Standbild (...) hinaufblicken ${ }^{61}$.

Das Stein-Denkmal allein reichte demnach zur Reminiszenz an die reformorientiert-progressive Nation nicht aus, da es auf dem Dönhoffplatz topographisch zu entlegen schien, während die Zentralität der Humboldt-Statuen an den Linden kaum zu überbieten war.

In der Würdigung besonders Wilhelm von Humboldts schwang gleichwohl Kritik an der Reichweite seines Verdienstes mit, indem dieser »die Befreiung des Vaterlandes vorbereitet[e], aber erfolglos für seine politische Freiheit strit $[t] \ll^{62}$. Daß der antinapoleonischen nicht die antireaktionäre Liberalisierung gefolgt war, verbuchte die National-Zeitung als beträchtliches Defizit, mit dem auch die Nation, für die die Kultfigur einstand, behaftet blieb. Wilhelm von Humboldts Kritik der Karlsbader Beschlüsse betonte die National-Zeitung anders als die feierlichen Einweihungsreden nachdrücklich ${ }^{63}$.

In Alexander von Humboldt sah sie nun den Gegner neuerlicher »Reaktionsversuche« inmitten des »Preußen der Manteuffel und Gerlach« und eine Verkörperung von auf Freiheit und Universalität gegründeter, öffentlich vermittelter $»$ Wissenschaft ${ }^{64}$. Die Wissenschaftspopularisierung wurde zur Metapher für eine antireaktionäre Vorwärtsorientierung der nationalen Gesellschaft, ohne daß der Transfer auf die politische Situation der zeitgenössischen Gegenwart des Kaiserreichs ausdrücklich geleistet worden wäre. Beide Denkmäler verbürgten am Ende nach der politischen Erwartung der National-Zeitung,

59 Vgl. NZ, 27. Mai 1883 (M.), S. 1-3, hier S. 1.

${ }^{60}$ NZ, 29. Mai 1883 (M.), S. 1.

61 Ibid.

62 Ibid

63 Vgl. ibid.

${ }^{64} \mathrm{Vgl}$. zu Humboldts Kritik an den Karlsbader Beschlüssen Rudolf VIERHAUS, Wilhelm von Humboldt, in: TREUE, GRUNDER (Hg.), Berlinische Lebensbilder, Bd. 3, S. 63-76. 
daß sich "Deutschland nach 1871 in die Tradition nicht der staatlichen "Zwangsgewalt«, sondern der freiheitlich-emanzipatorischen Reform stellte und $\mathrm{zu}$ »Fortschritt im Staate, Gesellschaft und Wissenschaft $\iota^{65}$ bekannte ${ }^{66}$.

Nicht anders als in Paris kamen auch in Berlin Denkmalstiftungen für renommierte Mediziner zustande ${ }^{67}$. Als Ende Ende Juli 1890 ein Denkmal für den Veterinärmediziner Andreas Christian Gerlach im Vorgarten der Tierärztlichen Hochschule in der Luisenstraße im Rahmen der Feierlichkeiten zum hundertjährigen Bestehen der Institution eingeweiht wurde, war bereits der Festplatz mit den "Farben der deutschen Lande« und dem Emblem des preußischen Adlers mit nationaler Symbolik versehen ${ }^{68}$. Im augenfälligen Gegensatz $\mathrm{zu}$ sonst gängigen Festbildern reknutierte sich die Festgesellschaft vor allem aus »Fachmännem[n] aus allen Theilen Europas ${ }^{69}$, darunter der französische Generalinspekteur der Veterinärschulen, Professoren aus der Schweiz, Dänemark und Österreich und zahlreiche Vertreter tierärztlicher Lehranstalten auch aus den nicht-preußischen Landesteilen ${ }^{70}$.

Die Reden wurden dazu genutzt, den Beitrag der tiermedizinischen Forschung für die "Gesammtheit der Wissenschaften« wie für die »Wohlfahrt des Volkes « namhaft $\mathrm{zu}$ machen ${ }^{71}$. Gerlachs Lebenswerk bot demnach Gelegenheit, einerseits den »medicinischen« Fortschrittlichkeitsbeitrag der Wissenschaft zur Nation zu betonen, andererseits mit ihr den »thierärztlichen Stand«

65

66 Vgl. ähnlich Berliner Tageblatt, 28. Mai 1883 (A.), LAB A Rep. 000-02-01 Nr. 1634, Bl. 92; Hermann GRIMM, Die Standbilder Alexanders und Wilhelms von Humboldt vor der K.Universität zu Berlin, in: Preußische Jahrbücher 51 (1883) S. 641-650.

${ }^{67}$ Mit einem Festumzug von Studenten blieb etwa die Einweihung des Denkmals für den Begründer der Augenheilkunde an der königlichen Charité Albrecht von Graefe ganz im Rahmen eines bürgerlichen Festes. Vgl. [Ad. SCHULZE,] Prof. Rudolf Siemering's A.v. Gräfe-Denkmal in Berlin. Enthüllt am 22. Mai 1882, Berlin 1882, S. 10; Stadtverordnetenversammlung von Berlin, 17. Mai 1882, in: SBSV 9 (1882) S. 230, 238. Ohne ausdrückliche nationale Konnotation erhielt auf Initiative eines Komitees von Ärzten auch der Mediziner Robert Wilms 1883 eine Bronzebüste gegenüber dem Hauptportal des ehemaligen Bethanienkrankenhauses. Vgl. Brief des Komitees an den König am 20. Oktober 1880, GStA PK I. HA Rep. 89 Nr. 20836, Bl. 66. Nur das Berliner Tageblatt, 30. Oktober 1882, LAB A Rep. 000-02-01 Nr. 1634, Bl. 101, wies darauf hin, daB Wilms auch auf einem der Reliefs der Siegessäule verewigt sei, die ihn als Offizier bei der Behandlung eines Verwundeten zeigte. Die Parallele zu den Pariser Larrey- und Londoner McGrigor-Denkmälern (vgl. dazu bereits Teil I, Kapitel IV), die ebenfalls der Figur des Militärarztes nationales Kultpotential zuschrieben, blieb zeitgenössisch unbemerkt.

${ }^{70} \mathrm{Zu}$ den ranghöchsten staatlichen Vertretern bei der Feier zählte lediglich ein Geheimer Rat aus dem Landwirtschaftsministerium. Anwesend waren aber u.a. der Rektor der Universität sowie mehrere studentische Korporationen aus Dresden, Hannover und Stuttgart.

71 Vgl. Prof Dr. Pütz, Gedächtnisrede bei Enthüllung des Gerlach-Denkmales am 30. Juli 1890 im Vorgarten des Königlichen Thierärtztlichen Hochschule zu Berlin, Berlin 1890, S. 1 und 5. 
im nationalen Ganzen zu verorten ${ }^{72}$. Wissenschaftsgesellschaft und Nation wurden schließlich demonstrativ parallelisiert, sofern in beiden Fällen der uneigennützige »Dienst« des »Einzelne[n] « zugunsten der »gemeinsamen Interessen « fundamental war, so daß die "Liebe zu Stand und Wissenschaft« und die »zu König und Vaterland« wesensverwandt erschienen ${ }^{73}$. Das Bekenntnis zur aufgeklärt-fortschrittlichen Nation blieb am Ende eng mit der Loyalität zum Kaiserreich verquickt, indem Wilhelm II. als Protektor der Forschung erschien, der die hochschulwissenschaftliche Anerkennung der Tiermedizin aus "landesväterliche[r] Fürsorge« unterstützt und nun auch deren prominentestem Vertreter die öffentliche Denkmalehrung zugestanden habe, so daß die Rede in einem vollmundigen Loyalitätsgelöbnis zum sauf dem festen Boden des Rechts und der Gerechtigkeit« stehenden Kaisertum gipfelte ${ }^{74}$. Derartige Wertund Erwartungsbegriffe wurden aber dem gängigen Herrscherlob eher beigemischt als selbstbewußt vorgetragen.

Auf die programmatische Kopplung von Wissenschaft und Nation zielte auch Enthüllung der Statue für den Physiker Hermann von Helmholtz 1899 im Vorgarten der Berliner Universität ab, der u.a. gemeinsam mit Werner von Siemens und Wilhelm Foerster 1890 als Mitbegründer und ehemaliger Präsident der Physikalisch-Technischen Reichsanstalt in Erscheinung getreten war $^{75}$. Hier übernahm nun erstmals in Berlin die Kaiserin in vollem Umfang, gleichwohl protokollarisch unterstützt vom uniformierten Kronprinzen als dem Repräsentanten der künftigen dynastischen Generation, die Rolle ihres abwesenden Gatten, indem sie nach dem Herrscherempfang den Enthüllungsbefehl erteilte und die übliche Nahinspektion unter den Erklärungen der Komiteemitglieder vornahm. Die Reden hatten allerdings wie schon der Subskriptionsaufruf vom Dezember $1894^{76}$ ein transnationales, anders als noch die Humboldtund die Gerlach-Feiern aber gänzlich entpolitisiertes Renommee Helmholtz' im Blick ${ }^{77}$. Helmholtz firmierte als großer nationaler Exponent der Grundlagenforschung und illustrierte den Reden zufolge die Teilhabe der Nation am globalen Wissenschaftsdiskurs durch ihren nationalen Protagonisten.

Ungleich politisierter wirkte demgegenüber ein zweites Denkmalfest noch im gleichen Jahr, in dessen Zuge sich die Perspektive vom internationalen Wissenschaftsdiskurs auf den anwendungsbezogenen industriellen Wettbe-

${ }^{72}$ Vgl. ibid. S. 5, 9

73 Vgl. ibid. S. 10

74 Vgl. ibid. S. 12

75 Vgl. zum Folgenden VZ, 6. Juni 1899, S. 2-3, hier S. 2; Freisinnige Zeitung, 7. Juni 1899 (Bbl.), S. 1. Zu den Festgästen zählten Vertreter staatlicher und städtischer Behörden und der Universität in »farbigen Amtstalaren«, daneben der Chef des kaiserlichen Zivilkabinetts von Lucanus.

76 Vgl. Aufruf zur Errichtung eines Denkmals für Hermann von Helmholtz, GStA PK I. HA Rep. 89 Nr. 20837, Bl. 89.

77 VZ, 6. Juni 1899, S. 2-3, hier S. 2. 
werb verlagerte und die Positionierung der Nation unter den internationalen Konkurrenten sprunghaft an Bedeutung gewann: Am 19. Oktober 1899 wurden im Kontext der hundertjährigen Jubiläumsfeierlichkeiten der Technischen Hochschule in Charlottenburg die Denkmäler für Werner von Siemens und Alfred Krupp im Vorgarten der Hochschule enthüllt ${ }^{78}$. Preußische und reichsdeutsche Dimensionen der nationalen Feier illustrierte der Festschmuck, indem die gesamte Charlottenburger Chaussee zur Triumphstraße mit »Reichsbannern« und Adler-Symbolen ausgestattet war, dazu blieben Region und Stadt mit dem Brandenburgischen und dem Charlottenburger Wappen präsent ${ }^{79}$. Ritus und Symbolik erschienen dennoch insofern bescheiden, als wenige Stunden später die zentrale Feier zum Jubiläum der Technischen Hochschule abgehalten wurde, zu der sich der Kaiser in Gesellschaft diverser Minister und umringt von einem stattlichen Militäraufgebot in Charlottenburg nicht nur persönlich einfand, sondern an deren Ende er sogar das Wort ergriff ${ }^{80}$. Die Denkmalenthüllung blieb demgegenüber zwar formal sekundär, rhetorisch sollte der Kaiser später allerdings durchaus auf sie zurückkommen, denn er verließ die Hochschule nicht, ohne demonstrativ »eingehend« die beiden neuen Denkmäler begutachtet zu haben. Damit war eine Art nachholende Präsenz des Monarchen für die Enthüllungsfeier hergestellt ${ }^{81}$.

Das Denkmalfest selbst nutzte der Vorsitzende des deutschen Ingenieurvereins Herrmann Bissinger zu einem wohlgefälligen Resümee zum Stand der Technik in der Moderne, deren »gewaltige Leistungen « und »ungeheure Fortschritte « die Feier faktisch zu einer solchen der »deutschen Technik« werden ließen ${ }^{82}$. Siemens und Krupp erschienen als Pioniere einer Schwer- und Elektroindustrie, die am Aufschwung der Wirtschaft seit der Reichsgründung beträchtlichen Anteil hatte. Der Vertreter des Vereins deutscher Eisen- und Stahlindustrieller Servaes legte Wert auf eine Würdigung, die die Maßstäbe der Produktivität noch sprengte, indem er Krupp darüber hinaus als wbedeutenden Menschen, den Wohltäter und väterlichen Freund seiner Arbeiter" apostrophierte und an die »Arbeiterkolonien« und »Wohlfahrtseinrichtungen « erinnerte, die auf Betreiben des Unternehmers entstanden waren ${ }^{83}$. Den Werkswohnungsbau würdigte Servaes als Mittel der Sozialpolitik, mit dem die Lebensbedingungen des in den Ballungszentren massenhaft entstandenen Industrieproletariats verbessert werden sollten. $\mathrm{DaB}$ Krupps paternalistische Po-

Vgl. zum Folgenden NZ, 19. Oktober 1899 (A.), S. 2; Germania, 20. Oktober 1899, S. 2; NPKZ, 19. Oktober 1899, S. 2.

79 Unter den Ehrengästen trat Kultusminister Konrad von Studt auf, daneben Vertreter anderer Technischer Hochschulen und der Berliner Universität in ihren Amtstrachten. Vgl. ibid

Vgl. NZ, ibid. S. 3; Germania, s.o.

${ }^{81}$ Vgl. dazu weiter unten.

82 Vgl. zum Folgenden NZ, 19. Oktober 1899 (A.), S. 2.

${ }^{83} \mathrm{Vgl}$. ibid. 
litik aber nicht zuletzt von der Sorge um eine soziale und politische Radikalisierung der industriestädtischen Arbeiterschaft beflügelt und insofern weniger solidarisch als vor allem domestizierend ausgerichtet gewesen war, blieb unerwähnt $^{84}$. Krupp verkörperte schließlich über Produktivität und Paternalismus hinaus eine erhöhte Präsenz des »deutschen Namen[s] (...) auf industriellem Gebiete in der ganzen Welt ${ }^{85}$ als Folge eines drastisch erhöhten deutschen Produktionsanteils an der Weltindustrieproduktion. Im Zentrum der euphorischen Expansions- und Exportbilanz stand das "Kruppsche (...) Kriegsmaterial«, das Servaes zufolge dazu beigetragen hatte, »die in vielen Ländern herrschende vorgefaßte Meinung gegen deutsche Erzeugnisse zu beseitigen«, so $\mathrm{da} ß$ es, sindem es den Absatz auch anderer deutscher Fabrikate im Ausland unterstützte und förderte, eine bedeutungsvolle Mission des Friedens ${ }^{86}{ }^{8 r}$ erfüllte. Damit war selbst Krupps Marktführerschaft in der Rüstungsindustrie nurmehr ein neuerlicher Beleg für seine zivilisatorische Gesinnung und seine ebenso protektive wie prestigeträchtige Funktion für die deutsche Wirtschaft. "Ausdauer, Entbehrung und Arbeit« bildeten die Tugendtrias, für die Krupp am Ende stand und die der Redner zur Nachahmung empfahl, damit die Nation ihre produktive Spitzenposition würde halten können.

Der Rektor der Technischen Hochschule rundete die emphatische Bilanz ab und blickte stolz "auf die großen Vorbilder deutschen Wirkens und Könnens, die den Erfolg der deutschen Technik in die ganze Welt getragen, Anerkennung des ganzen Auslandes erzwungen haben, nicht blo $\beta$ zum Ruhme der Technik, sondern auch des ganzen Reiches, der ganzen Nation ${ }^{87}$. Zum einen legte er so die quasi-imperialistische Ambition der Weltmarktdominanz offen, aus der sich auch ein spezifisches nationales Selbstbewußtsein speisen sollte. Zum anderen stellte er nun definitiv die »Technikheroen« den zuvor monumentalisierten »Heerführern[n] und Geistesfürsten« gleich. Damit weitete sich zugleich der Qualifikationsradius der »Nation« deutlich, weil zur modernen Nationsidee nun über die Frage der kriegerischen Bewährung und kulturellen Verankerung hinaus auch ihre Produktivkraft und internationale Wettbewerbsfähigkeit zu gehören schienen. Die Frage nach der Binnenkonstituierung der Nation, die sich im Zuge der ersten Berliner Projekte noch untrennbar mit dem Konzept der Fortschritts-Kultfigur verbunden hatte, wurde hier nun zugunsten der neuen, womöglich kompensatorischen Technik- und Fortschrittsfixierung zurückgestellt ${ }^{88}$.

${ }^{88}$ Krupp und Siemens illustrierten somit, daß sdas deutsche Volk nicht nur wie im vorigen Jahrhundert ein Volk der Denker blieb, sondern jetzt ein Volk des Schaffens ist«; vgl. ibid. 
Im Rahmen der nachfolgenden Jubiläumsfeier wertete Wilhelm II. nicht nur die zu diesem Anlaß mit dem Promotionsrecht ausgestattete Technische Hochschule als institutionelle Zugangsschleuse zum modernen Arbeitsmarkt ${ }^{89}$. Er rekurrierte auch auf die gerade eingeweihten Denkmäler und schaltete sich damit nachträglich in das Sinnstiftungsverfahren ein, indem er das bereits Gesagte bekräftigte und Krupp und Siemens als Garanten dafür erkannte, daß »die deutsche Technik im Wettkampf der Nationen allezeit ehrenvoll bestehen ${ }^{90}$ könne. War die internationale Dimension wissenschaftlichen und technologischen Fortschritts bis dahin vor allem anläßlich der Helmholtz-Feier eher als Voraussetzung zur Teilhabe an einem transnationalen Austausch eingestuft worden, betrieb Wilhelm II. hier nun ebenso programmatische wie propagandistische Engführungen, indem er das wissenschaftlich-technologische Leistungsvermögen als Modus zur Erlangung wissensstrategischer und machtpolitischer Vorteile zugunsten des Reichs umdeutete. Daß vor allem Krupp als Rüstungskonzern die besondere Protektion des Kaisers genossen hatte ${ }^{91}$, so daß die Beförderung von Produktivität und aggressive Außenverteidigung einer auf Machtkampf ausgerichteten Nation dicht beieinander lagen, führte der Kaiser nicht eigens aus.

Die Tageszeitungen reagierten auf die Denkmaleinweihung kaum mit expliziten Kommentaren, bekundeten aber Konsens mit der Ehrung, indem sie $\mathrm{mehr}^{92}$ oder minder ${ }^{93}$ ausführlich berichteten. Einzig der Vorwärts verbuchte die Abwesenheit des Kaisers offen als zeremoniellen und programmatischen Zugewinn und befreiende Entbindung von monarchischen Loyalitätsfloskeln ${ }^{94}$, verkannte dabei aber zugleich, wie Wilhelm II. es im Rahmen einer nachholenden Gestik und Semantik verstanden hatte, sich eben doch an den offiziösen Sinnstiftungen im Sinne des Machtstaats zu beteiligen. Unter dem Eindruck eines beträchtlichen Wirtschaftswachstums des Deutschen Reichs bestand insgesamt Konsens über die Modernisierungs-, Expansions- und womöglich wirtschaftlichen Imperialismus-Erfordernisse, denen die Nation sich nun um die Jahrhundertwende zu stellen hatte. An keiner Stelle wurde indessen im Zusammenhang mit den beiden Denkmaleinweihungen für Siemens und Krupp die soziopolitische Innenausstattung dieser nun auf Effizienz und Produktivität geeichten Nation thematisiert.

Vgl. dazu auch Christian SIMON, Kaiser Wilhelm II. und die deutsche Wissenschaft, in: RöHL (Hg.), Der Ort Kaiser Wilhelms II., S. 91-110.

90 Ibid. S. 3 und NPKZ, 19. Oktober 1899, S. 3.

91 Vgl. Hartmut POGGE vON STRANDMANN, Der Kaiser und die Industriellen. Vom Primat der Rüstung, in: RÖHL (Hg.), Der Ort Kaiser Wilhelms II., S. 111-129.

93 Vgl. NPKZ, 19. Oktober 1899, S. 2-3; Germania, 20. Oktober 1899, S. 2; Freisinnige Zeitung, 20. Oktober 1899 (Bbl.), S. 1-2.

$94 \mathrm{Vgl}$. Vorwärts, 21. Oktober 1899 (1. B.), S. 2 
$\mathrm{Zu}$ den wenigen "Erfindern «, die in Berlin in ausdrücklich nationaler Absicht und darüber hinaus in einem spezifisch kleinbürgerlich und erstmals von sichtbaren Symbolkonflikten geprägten Umfeld zu Denkmalehre kamen, zählte schließlich das Denkmal, das am 6. November 1892 der Lithograph Alois Senefelder zum 121. Jubiläum seines Geburtstages auf dem gleichnamigen Platz bei der Schönhauser Allee im Norden Berlins erhielt. Ähnlich wie die Gerlach-Feier, wenn auch weniger international, prägte ein weiterer Einzugsbereich der Festgesellschaft die Szene, indem sich nicht nur Mitglieder der Ortskrankenkasse, Steindrucker und Lithographen beteiligten, sondern neben Vertretern der Stadtverordnetenversammlung und des Magistrats auch Abordnungen aus Dresden, Leipzig, Bautzen, Hannover und anderen Städten sowie aus Senefelders Geburtsort Prag ${ }^{95}$. Nachdem die Hülle gefallen und die Hymne gesungen war, legten Vertreter verschiedener Firmen und Vereine einschließlich der Berliner Handwerkerschule Kränze nieder ${ }^{96}$. Der Kaiser war zur Feier des Repräsentanten deutscher »Kultur und Civilisation « nicht nur im »engeren Vaterlande«, sondern auch im Ausland ${ }^{97}$ eigens geladen worden, aber nicht erschienen. In der Festansprache des Komiteevorsitzenden wurde Senefelder als Inspirator der Kunst, Wissenschaft und Industrie gefeiert, bevor man mit Hochrufen auf den Kaiser schloß $\AA^{98}$.

Im Hintergrund der harmonischen Inszenierungen standen nun allerdings handfeste Konflikte. Die Vossische Zeitung wußte zu berichten, daß sozialdemokratische Steindrucker und Lithographen, Hilfsarbeiter und Arbeiterinnen sich nicht beteiligten, sondern statt dessen als konkurrierende Veranstaltung eine öffentliche Versammlung waller Buchdrucker« einberufen hatten, »um dort eine eigene Feier vorzunehmen «" ${ }^{99}$. Im mit Kränzen, roten Fahnen und sozialdemokratischen Inschriften geschmückten Versammlungslokal hatte man einer Senefelder-Büste diejenige des Gründers des Allgemeinen Deutschen Arbeitervereins Ferdinand Lassalle zur Seite gestellt und dadurch symbolträchtig das berufsständische mit dem parteipolitischen Votum verquickt, Senefelders Exempelfunktion also weniger mit nationalen als mit sozialistischen Ideen in Verbindung gebracht. Die symbolische Zuordnung signalisierte zugleich vehemente Ambitionen der Arbeiterbewegung auf eigenes Kultpersonal, dem Lassalle seit Mitte der 1860 er Jahre verbindlich zugehörte ${ }^{100}$. Erst am späten Vormittag begaben sich Teile der etwa 1.000 Personen umfassenden

Vgl. NZ, 7. November 1892, S. 3. Als Vertreter des Kultusministeriums erschienen der Direktor der Nationalgalerie, daneben von Zieten vom Generalstab.

Vgl. VZ, 7. November 1892 (1. B., A.), S. 5.

Vgl. Einladungsschreiben vom Oktober 1892, GStA PK I. HA Rep. 89 Nr. 20837, BI. 34.

Vgl. VZ, 7. November 1892 (1. B., A.), S. 5.

Ibid.

${ }^{100}$ Zum Lassalle-Kult vgl. KORFF, Politischer »Heiligenkult«, S. 211-217; Amo HERZIG, Die Lassalle-Feiem in der politischen Festkultur der frühen deutschen Arbeiterbewegung, in: DƯDING, FRIEDEMANN, MƯNCH (Hg.), Öffentliche Festkultur, S. 321-333. 
Festgesellschaft nicht in einem Demonstrationszug, wohl aber in kleinen verstreuten Gruppen zum bereits eingeweihten Monument, um dort Kränze niederzulegen ${ }^{101}$. Die Aufschriften der Kranzschleifen, die die sozialdemokratischen Gruppierungen postierten, lasen sich in der Tat als durchaus unverhüllte Provokation der harmonistischen Deutungsmuster, die die Festredner zu propagieren versucht hatten: der Kranz der Lithographen und Steindrucker betonte, daß »nur Einzelnen [Senefelders] Erfindung lohnenden Verdienst [einbrachte], nicht aber den Hunderttausenden [seiner] Jünger « während der Kranz der Arbeitslosen den Umstand brandmarkte, daß diese "trotz [Senefelders] Schöpfung in Folge zu großer Ausbeutung brotlos umherirren und keinen lohnenden Erwerb [hatten] ${ }^{102}$. Indem sie die Realität massiver sozialer Ungleichheit hervorhoben, bestritten die konkurrierenden sozialdemokratischen Denkmaldeuter nicht die Exempelfunktion des Erfinders der Lithographie für die kulturelle Produktivität der Nation. Sie widersetzten sich aber öffentlich der Diktion der offiziellen Festreden, die Senefelder kritiklos und mit idealisierenden Aussparungen mit der monarchischen Nation assoziierte.

Bereits die Dissoziierung der Kulthandlungen hatte die Unvereinbarkeit konkurrierender Deutungsmuster offenbart, indem die Sozialdemokraten das Monument nicht primär im Namen der Nation, sondern einer sozialistischen Solidarität durch eigene Riten symbolisch in Besitz nehmen wollten. Sowohl dem kleinbürgerlichen Profil der Festgesellschaft als auch dem Loyalitätskonflikt nach blieb die doppelte Senefelder-Feier ebenso Ausnahmefall wie untrügliches Indiz für den Bedarf an eigenen Kulthandlungen und Sinnorientierungen seitens der politischen Linken wie auch für den Umstand, daß die Fortschrittsassoziation ähnlich wie die von Wissenschaft und Forschertum für die Entwicklung transnationaler Zielutopien besonders anknüpfungsfähig erschien.

\section{London: Zur Marginalität eines Deutungsmusters}

Inszenierung und öffentliche Resonanz von Monumenten, die Exponenten des technischen Fortschritts huldigten, blieben in London äußerst bescheiden. Ohne öffentliche Feier hatte bereits kurz nach der Jahrhundertmitte die Aufstellung einer kolossalen Marmorstatue für den Eisenbahningenieur George Stephenson im April 1854 in der großen Bahnhofshalle am Euston Square im Norden Londons stattgefunden ${ }^{103}$. Über die öffentliche Ehrung setzte sich die

${ }^{101}$ Vgl. VZ, 7. November 1892 (1. B., A.), S. 5.

${ }^{102} \mathrm{Vgl}$. ibid.

${ }^{103}$ Vgl. The Times, 3. Januar 1853, S. 5; ibid. 11. April 1854, S. 10. Vgl. Harry HEARDER, Europe in the nineteenth century 1830-1880 (A general History of Europe), Burnt Mill, 
Presse aber weitgehend hinweg ${ }^{104}$. Die Kultkonjunktur der Fortschrittshelden blieb insofern gleichermaßen schlecht.

Von der 1871 in der Mitte des Euston Square plazierten Statue für Georges Sohn Robert Stephenson, der nicht nur an den großen Projekten seines Vaters im Norden Englands mitgewirkt, sondern den Streckenausbau seinerseits in den Midlands und im südlichen England betrieben hatte, wurde jenseits floskelhafter Erwähnung ${ }^{105}$ kaum zur Kenntnis genommen ${ }^{106}$. Die Transportrevolution, obschon eine der zentralen Stützen der Industrialisierung, schien kein kultfähiges Thema. Etwas öffentlichkeitswirksamer erschien die Monumentalisierung des Erfinders des "penny postal-system» Sir Rowland Hill im Juni 1882 an der südwestlichen Seite des Royal Exchange ${ }^{107}$. Hier prägte ein vergleichsweise aufwendiges städtisches Ritual die Festveranstaltung, als vor dem Denkmal der Lord Mayor, mehrere Sheriffs und unter den Gästen zahlreiche Bürgermeister aus verschiedenen Provinzstädten zusammenkamen und die in Roben erschienenen Amtsträger dem Festbild einen eher munizipalen Charakter verliehen. Freilich blieb auch hier die Titulierung Hills als exemplarischer "Englishman«, »distinguished countryman« und Beförderer ebenso nationalen wie internationalen Fortschritts, die der Prince of Wales eigens vornahm, eher floskelhaft ${ }^{108}$. Der Evening Standard entfaltete vom Penny Postage-System her, das "for the great bulk of mankind, abolished distance ${ }^{109}$, die Vision der Nation als egalisierte und globalisierte Kommunikationsgemeinschaft, die dank »magnitude and progress« des Erfinders ihrer Realisierung ein Stück näher gekommen war ${ }^{10}$.

Gänzlich anderen Bedingungen unterlag schließlich eine späte, komplett von der Empire-Thematik überlagerte Denkmalstiftung, die erst Anfang Juli 1914

Harlow ${ }^{2} 1988$, S. 75-80. Nur etwa ein Dutzend Männer waren vor dem Denkmal zusammengekommen.

${ }^{104} \mathrm{Vgl}$. The Times, 11. April 1854, S. 10.

${ }^{105}$ Vgl. The Illustrated London News, undatiert, Camden Local Studies and Archives Centre, Holborn Library 53.5 Stepenson/Ephemera file on statue of R. Stephenson in Euston Square [up].

${ }^{106}$ Ähnliches galt für das Denkmal, das Isambard Kingdom Brunel im Juli 1877 in den Victoria Embankment Gardens erhielt. Vgl. Sitzung des MBW am 20. September 1871 und am 13. Oktober 1871, in: Minutes of Proceeding of the MBW Juli-Dezember 1871, 282/59 und 347/7 sowie Sitzung des MBW am 6. Juli, 27. Juli, 5. Oktober 1877, in: Minutes JuliDezember 1877, 17/8; 149/32, 340/10. Vgl. HEARDER, Europe in the nineteenth century, S. 81 . Hinweise auf eine Einweihung fehlen.

${ }^{107}$ Vgl. zum Folgenden The Times, 19. Juni 1882, S. 7.

${ }^{108}$ Vgl. ibid.

${ }^{109}$ Evening Standard, 19. Juni 1882, S. 4.

${ }^{110}$ Vgl. ibid. Das Denkmal geriet wenige Jahre später kurzfristig in den Fokus einer erhitzten Debatte über die Urheberschaft der Postreform. Vgl. [Patrick CHALMERS,] Who invented Uniform Penny Postage? Change of inscription upon the city statue of Sir Rowland Hill. Declaration of the Treasury, London 1884; [DERS.,] To the Chairman and Members of the Board of Commissioners of Sewers, of the City of London, $\mathbf{0 . 0}$. o. J. 
am östlichen Ende der Mall für den Entdecker James Cook nahe dem Admiralitätsgebäude zustande kam und in deren Folge zugleich das erste und einzige der freistehenden Personendenkmäler entlang der "processional route« entstand, die nach den Plänen des Architekten Webb anläßlich von Begradigung und Ausbau der Mall im Zusammenhang mit dem Bau des Victoria Memorials 1911 ursprünglich in größerem Umfang vorgesehen gewesen waren ${ }^{111}$.

Ein außergewöhnliches $\mathrm{Maß}$ an offiziöser und militärischer Inszenierung und die Enthüllung des Denkmals zu den Klängen der populären imperialistischen «Rule Britannia«-Hymne ließen bereits das festliche Prozedere erkennen, das mehrere hochrangige Militärs und Vertreter der imperialistischen British Empire League verfolgten ${ }^{112}$. Die offiziellen Redner unterstrichen zunächst, daß von den Expeditionen des "surveyor and discoverer" Cook nicht nur die britische Krone, sondern die Welt profitiert habe und erachteten angesichts dessen, daß andernorts in der Tat bereits öffentliche Monumentalisierungen Cooks stattgefunden hatten, die Denkmalerrichtung in der Kapitale für dringlich $^{113}$. Besondere Bedeutung maß man dem denkmaltopographischen Arrangement zu, das sich aus der Plazierung der Statue in unmittelbarer Nähe des Admiralitätsgebäudes als Hort der »naval supremacy« ergab, und verstand damit die machtpolitische Dimension der Empire-Erweiterung als zentralen Gründer-Effekt von Cooks Expeditionen: „There are few chapters in our Empire's history more characteristic of the true nature of British expansion than that contained in the history of Captain James Cook, (...) he was the father of the master builders of Greater Britain ${ }^{114}$. Zitiert wurden die Forschungsreisen, die Cook während der 1770er Jahre im Auftrag der Royal Society geleitet hatte und die ihn am Ende auf der Suche nach der Nordwestpassage zur Entdeckung Hawaiis geführt hatten.

$\mathrm{Da}$ es längst eine hagiographisch und mythisch aufbereitete Erzählung und zahlreiche bildliche Darstellungen insbesondere dieser letzten Expedition gab, deren Höhepunkt der Legende nach 1779 zuerst in der apotheotisch-

${ }^{111}$ Vgl. Earle an Webb, 13. Februar 1914, PRO Work 20/79 [up].

${ }^{112}$ Eine Ehrenformation der Marine und eine Abordnung australischer Kadetten hatten sich formiert; unter den Ehrengästen befanden sich neben zahlreichen prominenten "Colonial Statesmen « der First Sea Lord of the Admiralty Prinz Louis von Battenberg und der liberale Staatssekretär des Marineministeriums Thomas Macnamera. Vgl. The Daily Telegraph, 8. Juli 1914, 14; The Times, 8. Juli 1914, S. 10; sehr knapp The Standard, 8. Juli 1914, S. 12.

${ }^{113}$ Vgl. ibid. Bereits 1874 war ein Cook-Denkmal im Hyde Park von Sydney/Australien entstanden. Im November desselben Jahres errichtete man, auf 1877 an die britische Krone gekommenem Boden, auch einen Obelisken an der Westküste von Hawaii, vgl. John Wesley COULTER, Great Britian in Hawaii: The Captain Cook Monument, in: The Geographical Journal 130 (1964) S. 256-201.

114 Ibid. 
verklärenden Verehrung Cooks durch die Eingeborenen bestand ${ }^{115}$ und doch wenig später mit seiner tragischen Ermordung endete, blieb unerwähnt. Insofern vermied man es zugleich, die der mythischen Erzählung zugrundeliegende schablonenhafte Entgegensetzung von (religiösen) Archaismen der Indigenen und zivilisatorisch-rationaler Kultursuprematie der britischen Nation wiederaufzugreifen ${ }^{116}$. Vom Mitbegründer des Empire Cook schloß man statt dessen programmatisch zur Empire-Nation auf: „Our Empire is not only the most vast and the most prosperous that the world has ever known, it is also the most scattered. It is (...) >a world Venice with the sea for streets.\& By the sea our Empire is divided and by the sea it is also held together ${ }^{117}$. Expansion und Festigung der imperialen Weltmachtstellung wurden damit nicht nur erneut als unabdingbare Voraussetzung nationaler Statuswahrung gewichtet, sondern mit der Venedig-Metapher zugleich ästhetisiert und dem traditionsreichen Bild von der insularen Sonderexistenz Großbritanniens und nun eben auch des Empire einverleibt.

In der Presse war für die Inszenierung zunächst breite Zustimmung zu ernten. Repräsentativ nahm sich der Artikel des Daily Telegraph aus, der Cook als Gründer und Mehrer der Empire-Besitzungen und daher als "good and faithful servant of the nation « titulierte, darüber hinaus aber auch als international bedeutsamen Vertreter wissenschaftlichen Fortschritts ${ }^{118}$. Anzeichen nicht nur genereller Denkmalmüdigkeit, sondern auch anhaltender Skepsis gegenüber der imperialen Euphorie, die im Umfeld des Denkmals erneut auszubrechen schien, waren hingegen im linken Guardian erkennbar, der zur "League that looks after the British Empire for us" ebenso auf Distanz ging wie zu jenem "good deal of Imperialistic eloquence $\ll$, zu dem sich die Festredner verstanden hatten. Durch seinen lakonischen Ton jedenfalls signalisierte der Guardian, daß er das Monument höchstens als Projektionsfläche der League, nicht indessen als national verbindliches Symbol anzuerkennen bereit $\operatorname{war}^{119}$.

Bei aller selbstsicher und weithin konsensual vorgetragenen EmpireRhetorik blieben konkrete Feindbildassoziationen, die sich aus dem Postulat eigener Machtreichweite hätten ergeben können, zumindest anläßlich der Denkmaleinweihung aus; auch die Flottenagitation blieb im Rahmen der Hin-

${ }^{115}$ Vgl. zum Cook-Mythos Marshall SAHLINS, How »Natives« think, About Captain Cook for example, Chicago 1995. Vgl. kritisch Gananath OBEYESEKERE, The apotheosis of Captain Cook. European mythmaking in the Pacific, Princeton 1997, S. 3, 7f., 49-60; William H. SEWELL JR., Eine Theorie des Ereignisses. Überlegungen zur smöglichen Theorie der Geschichter von Marshall Sahlins, in: Andreas SUTER, Manfred HETTLING (Hg.), Struktur und Ereignis, Göttingen 2001 (GuG Sonderheft, 19), S. 46-74, hier S. 50.

${ }^{116} \mathrm{Vgl}$. The Daily Telegraph, 8. Juli 1914, S. 14.

${ }^{117}$ Ibid

118 Ibid.

${ }^{119}$ Vgl.The Guardian, 7. Juli 1914, S. 8. 
weise auf den britischen Seemachtstatus implizit. Selbst die imperiale Emphase des Denkmalfestes wurde sprachlich durchaus weniger aggressiv vermittelt, als dies noch für die programmatischen Verlautbarungen anläßlich der Denkmäler für die Militärs seit Ende der 1880er Jahre der Fall gewesen war. Der Universalitätsschub, den die Idee von Forscher- und Entdeckertum vor allem in Frankreich dem Nationsbegriff hatte verleihen können, war andererseits von keinem Londoner Denkmal in der heterogenen Reihe von Fällen programmatisch genutzt worden und erschien nun 1914 ohnedies von imperialer Rhetorik überlagert $^{120}$.

\section{Vergleich}

Ein wirkliches Zeremoniell kam in London bei den Denkmalerrichtungen für die Vertreter des Fortschritts nicht zustande und hielt sich auch in Paris in äuBerst bescheidenen Grenzen. Den ebenso exklusiven wie artifiziell-theaterhaften und routinierten Charakter Pariser Inszenierungen, der freilich nicht an das spezifische Personal gebunden war, sondern hier nur gelegentlich markanter hervortrat, dokumentierte die Einweihung des Leblanc-Denkmals Ende der 1880er Jahre, bei der es gleichsam auf Publikumswunsch zu einer »Wiederholungsvorstellung« kam, mit der kurzzeitig ein gewisses Maß an Öffentlichkeit hergestellt wurde, bevor die Elite sich erneut zurückzog. Um die Jahrhundertwende erlebten die Pariser Denkmalfeste etwa im Rahmen der PasteurFeier mit einer größeren Festgesellschaft und mehr öffentlichem Nachhall noch einmal eine regelrechte Konjunktur.

In Berlin zählten die Denkmäler für Repräsentanten des Fortschritts anders als in Paris durchaus zu den prominenter inszenierten Monumenten. Die Einweihung der Humboldt-Denkmäler ließ der Kaiser in der Nähe des monarchischen Repräsentationszentrums Unter den Linden zu, hielt sich aber zunächst bedeckt, um am Ende doch die Festszene mit einem Kurzauftritt zu beherrschen. Ungeachtet militärischer Festgäste und Marschmusik nahm das Programm dennoch keine dominant militärischen Züge an, während der Flaggenschmuck die über Preußen hinausreichende Dimension der Nation andeutete, die gefeiert werden sollte. Anläßlich der Enthüllung des Helmholtz-Denkmals trat der seltene Fall der Leitung des Zeremoniells durch die Kaisergattin auf, der aber nicht etwa programmatisch für geschlechtsspezifische Emanzipation

${ }^{120}$ Außerhalb der Denkmalkultur hat es aber im England der 2. Hälfte des 19. Jhs. durchaus nicht anders als in Frankreich und Deutschland eine propagandistische Nationalisierung der Wissenschaft gegeben, vgl. Ludmilla JARDANOVA, Science and nationhood: cultures of imagined communities, in: CUBITT (Hg.), Imagining nations, S. 192-211. 
stand. Darüber hinaus entfielen militärische Festelemente, während statt dessen Lorbeerkränze und Palmwedel am Denkmal niedergelegt wurden. Mit militärischer Symbolik kamen allerdings die Siemens- und Krupp-Denkmäler durch den nachträglichen Auftritt des Kaisers doch mittelbar wieder in Berührung. Im für Berlin anders als für Paris seltenen Fall der rituellen Dissoziierung vor dem Senefelder-Denkmal spiegelten sich erstmals konfligierende Kulterwartungen der politischen Linken wider, die mit dem traditionellen Mittel der Kranzschleifeninschriften alternative Deutungen für das Monument namhaft zu machen versuchte. Daß in der transnationalen Deutungsoption, die im Blick auf das Fortschritts-Personal zu entwickeln war, Sprengkraft für die politische Opposition auch im Kaiserreich lag, blieb hier ebenso vage wie episodenhaft angedeutet.

Die Konjunktur naturwissenschaftlicher Forschung und technologischen Fortschritts und ihr Legitimationspotential für das Selbstbild der modernen Nation haben sich jedenfalls in den Denkmallandschaften aller drei Kapitalen programmatisch nachdrücklich niedergeschlagen. Argumentativ schlüssige Verbindungen mit Modernitäts- und universalen Humanitätskriterien der $\mathrm{Na}$ tion und eine entsprechend transnationale Ausrichtung nach außen und zumindest rhetorische soziale Inklusion ließen den nationalen Diskurs im Kontext dieser Denkmalkategorie vor allem in Paris zunächst als einen der offensten und unparteiischsten erscheinen. Als prominent erwies sich der Exempelstatus renommierter Mediziner, deren Therapieerfolge je neu den Progreß von einer dubios-veralteten Heilkunde hin zu einer effizienten medizinischen Diagnostik dokumentierten, oder der Chemiker, die der modernen Nation zu autarker Ressourcenmobilisierung verhalfen. Beide verkörperten die Nation als karitativhumanitäre, solidarische und international vorbildliche Gemeinschaft.

Freilich erschien die nationale Formel im programmatischen Zusammenhang der Pariser Denkmaleinweihungen bisweilen auch gesucht und kaschierte gelegentlich den Umstand, daß Initiatoren das nationale Etikett unter Anpassung an politische Konjunkturen dazu nutzten, ihre Projekte erfolgreich zu betreiben, während sich umgekehrt städtische und staatliche Autoritäten mit der Gewährung der Initiativen zugleich zu Objekten öffentlicher Respekts- und Loyalitätsbekundungen machten und die Festivitäten dann auch zum öffentlichen Auftritt in eigener Sache nutzten.

Diese doppelte Vehikelfunktion der Nation-Fortschritts/Wissenschafts-Thematik und ihres Personals stie $B$ indessen rasch an rezeptive Grenzen. Den Eindruck konsensträchtiger nationaler Kultfiguren konterkarierten nämlich häufig öffentliche Kommentare, die die nationale Verbindlichkeit angesichts spezifischer politischer oder areligiöser Prägungen für problematisch erachteten. Namentlich die konservative und katholische Presse vermißte ungehalten christliche Sinnhorizonte und argwöhnte metaphysikfeindlichen Rationalismus. Die republikanischen Presseorgane unterdessen wachten sorgsam dar- 
über, daß sich über die Fortschrittsemphase keine unreflektierten oder manipulativen Idealisierungen der Revolution von 1789 in die Denkmalprogrammatik einschlichen und klopften selbst die profiliertesten Forscherviten auf politische Affinitäten zum autoritären Empire ab, um ungewollten Legitimierungen oder Kontinuitätskonstrukten Einhalt zu gebieten.

In beiden Fällen signalisierte der Einspruch, der mit Voranschreiten des Jahrhunderts immer öfter erhoben wurde, eine steigende Sensibilität für Deutungshoheiten zum einen und gleichsam zulässige oder erwünschte Loyalitätsamalgame im nationalen Diskurs zum anderen. Internationalismus, globaler Fortschrittsoptimismus und humanitäre Vision blieben aber dessenungeachtet die zentralen Sinnbezüge für die national konnotierten Forscherdenkmäler in Paris, die mit der Jahrhundertwende und vor allem mit der Pasteur-Feier noch einmal einen regelrechten Boom erlebten, dabei allerdings je neu wieder nach den alten Kriterienrastern durchleuchtet und entsprechend kritisiert wurden. Die wirklich globalen Projekte für eine international konzipierte Feier von Newton und Galilei erwiesen sich, mutmaßlich auch aufgrund der Nationalität der anvisierten Kultfiguren, als nicht realisierbar; damit schien das visionäre Potential der transnationalen Rhetorik doch überlastet.

Berliner Denkmalsetzer tasteten sich an wissenschaftliches Personal zum Zweck nationaler Konnotierung deutlich langsamer heran, als dies für Paris gelten konnte. Die doppelte Denkmalehrung für die Humboldtbrüder Anfang der 1880er Jahre gab Gelegenheit, neben den preußischen Reformen auch Wissenschaft und Fortschritt als Symptome der Vitalität und Modernität der preußischen und nun der Reichsnation zu identifizieren. Der Bezug der solchermaßen verhandelten Nationsidee zur Monarchie blieb ambivalent. Einerseits sparten die Reden die Assoziation des Kaisers nicht nur aus, sondern lieferten eine Synopse der zeitgenössischen Denkmaltopographie, in dem die Monarchenmonumente gar nicht vorkamen; andererseits war die Plazierung des Denkmals nahe des monarchischen Repräsentationszentrums überhaupt nur mit monarchischem Plazet denkbar und beherrschte am Ende der Kaiser die Festszene.

Eine ausgefeilte Programmatik zur Nationalisierung der Wissenschaft, wie sie allerdings auch in Paris erst Ende der 1880er Jahre allmählich in größerem Stil entwickelt worden war, blieb hier noch aus. Der Appell an emanzipatorische Potentiale der Bildung und internationale Kooperation im Zeichen der Wissenschaft prägte nur die Reden in der späteren, nicht mehr im Anblick der Monumente stattfindenden Humboldt-Feier. Auch die liberale Presse reichte eine Politisierung der Kultfiguren auf der Seite der liberalen und antireaktionären Nation nach und griff zugleich den Gedanken universaler Freisetzung jenseits staatlicher oder nationaler Verengung auf. Mit dem Berliner GerlachDenkmal traten demgegenüber deutliche Ähnlichkeiten mit dem monumentalen Diskurs in Frankreich auf, indem die Kopplung von Wissenschaft und Na- 
tion gleichermaßen zur Selbstverortung der Forscher in der modernen Nation wie zum Entwurf eines global-offenen Nationsbilds diente. Ebenfalls ähnlich wie in Frankreich bestand hier die Neigung, Fortschrittserfolge nun nicht der republikanischen, sondern der monarchischen Nation zuzuschreiben und der Feier empirisch-rationaler Forschungserfolge zugleich Legitimationsargumente für die politische Gegenwart abzugewinnen. Die Assoziation von Kaisertum und Reich erfolgte unter der neuen Themenvorgabe zunächst jenseits machtund militärstaatlicher Konnotierungen und eröffnete von daher einen gleichsam entmilitarisierten Blick auf die politische Nation; diese Deutungsoption ist aber nicht gezielt weiterverfolgt worden. Eine ähnlich idealistisch bereinigte Nationsidee lag der Helmholtz-Feier zugrunde, deren Diktion zufolge ihre Bestimmung am ehesten im universalen Geistesdiskurs lag, während sie sich zu weit verflüchtigte, um inneren oder äußeren, politischen und institutionellen Konturen nach sichtbar zu werden.

Noch Ende der 1890er Jahre kippte aber der Diskurs um die Berliner Siemens- und Krupp-Denkmäler zu einer pragmatisch und dezidiert machtpolitisch inspirierten Idee von der Nation, der produktive Energien zu ökonomischer Expansion und machtpolitischem Bedeutungszugewinn verhalfen und die das internationale Terrain weniger als Chance zum globalen Austausch denn als Parkett für rigide Einflußwettbewerbe nutzen mußte. Die Belastung des Leitbilds transnationaler Kooperation durch einen ausgeprägten imperialen Ehrgeiz erwies sich somit bereits am Vorabend des Krieges als Spezifikum deutscher Denkmaldeutungen ${ }^{121}$. Die Gleichberechtigung der Technikheroen mit den Dichtern und Denkern als nationale Kultfiguren wurde bewußt als Abkehr von einer machtpolitisch lähmenden, kompensatorischen Kulturnationsidee und als eine Art quantitativer Umschlag nationaler Entwicklung stilisiert, indem Kreativität nur noch zählte, wenn sie sich materialisieren ließ und Konkurrenzpotentiale mit dem Ziel der Dominanz vermittelte. Anders als in Frankreich blieb Kritik am neuen Deutungsmuster aus, indem weder Metaphysikverlust einer konfessionell konnotierten Nationsidee noch vorzeitige Solidarisierung mit dem monarchischen Staat im Zuge der Fortschrittsrhetorik problematisiert wurden.

In weniger euphorischem Maßstab als anläßlich der Pariser Newton- und Galilei-Projekte, aber mit ähnlich transnationaler Stoßrichtung versuchten auch in Berlin Sozialdemokraten das Senefelder-Denkmal zur Projektionsfläche einer internationalen Solidaritätsgemeinschaft zu machen. Während die Pariser Initiative nie umgesetzt wurde, gelang in Berlin die nachträgliche Umdeutung

${ }^{121}$ Dieser Befund konvergiert mit der Diagnose Föllmers zum Nationsbild deutscher und französischer Industrieller vor 1914, vgl. Moritz FOLLMER, Die Verteidigung der bürgerlichen Nation. Industrielle und hohe Beamte in Deutschland und Frankreich 1900-1930 (Kritische Studien zur Geschichtswissenschaft, 154), Göttingen 2002, S. 95. 
kaum, blieb ein konservativ geprägter Deutungskontext ausschlaggebend, der die Fortschritts- und Erfindungsleistung auf die monarchische Nation festlegte.

Demgegenüber lag die Fortschrittsthematik in der öffentlichen Denkmallandschaft Londons über weite Strecken brach und deutete sich lediglich in vereinzelten Projekten an. Die einzige große Inszenierung, die zu einer ähnlichen Personenkategorie zustandekam, unterlag mit dem Cook-Denkmal 1914 allerdings längst einer dominanten Überformung des Entdecker-Topos mit imperialistischen Floskeln, indem noch massiver als im Zusammenhang mit den Berliner Krupp- und Siemens-Denkmälern, allerdings auch in viel unmittelbarerer Nähe zum Kriegsausbruch, Internationalität nicht als globale Diskursoption, sondern als Eröffnung einer neuen Machtkampfarena eingestuft wurde. 

Abb. 1

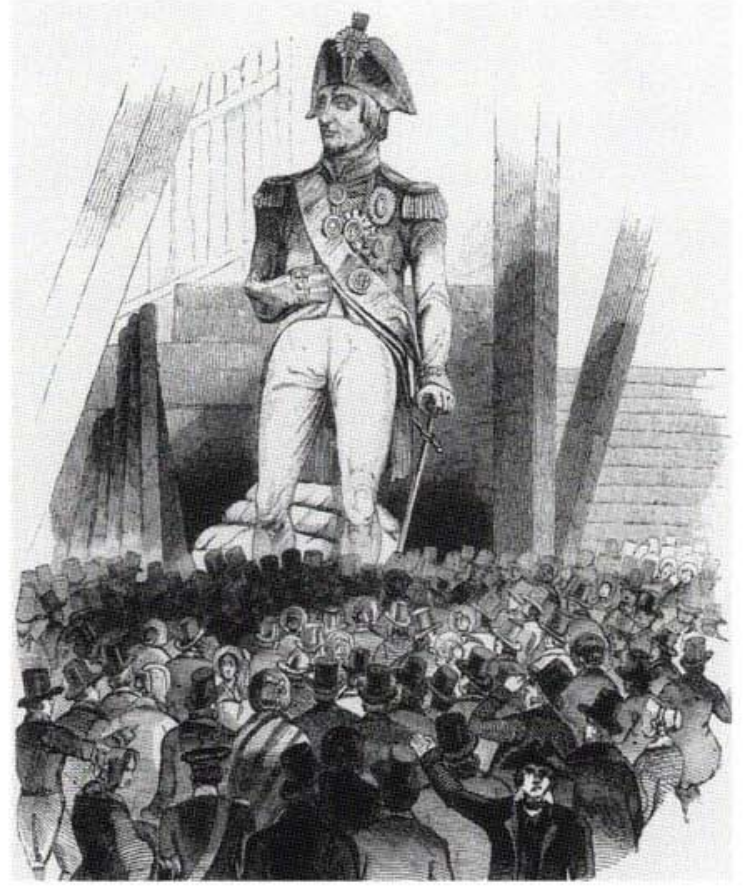

Abb. 2

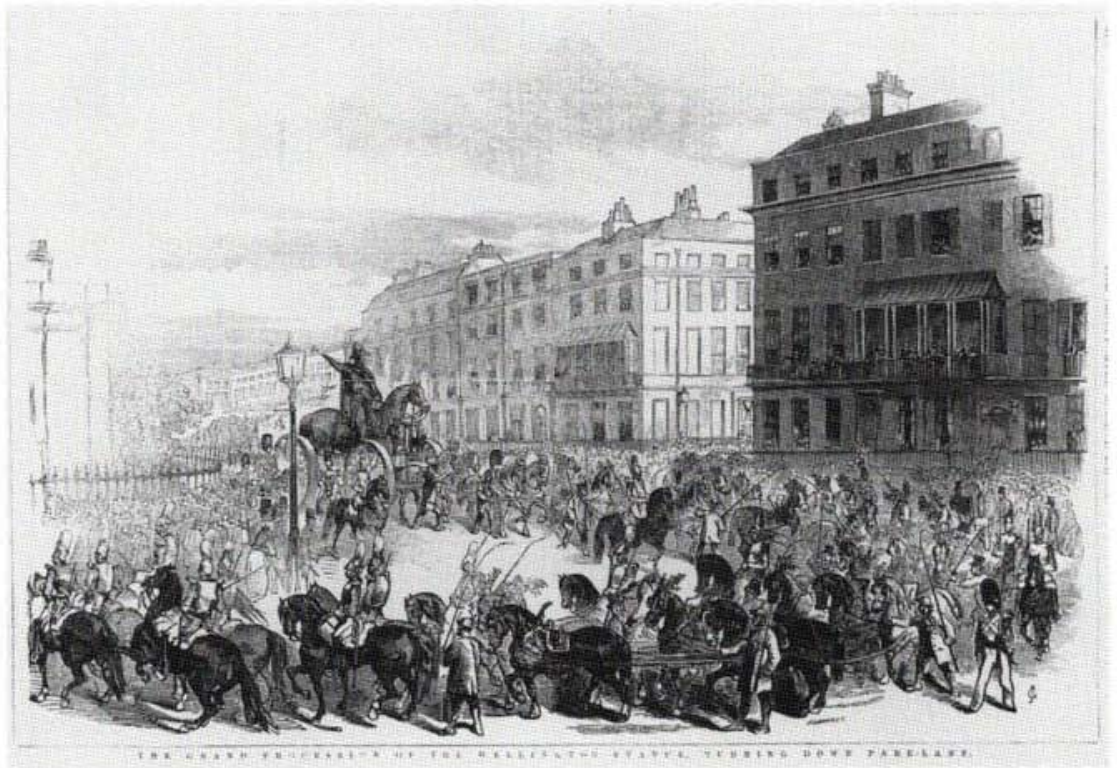




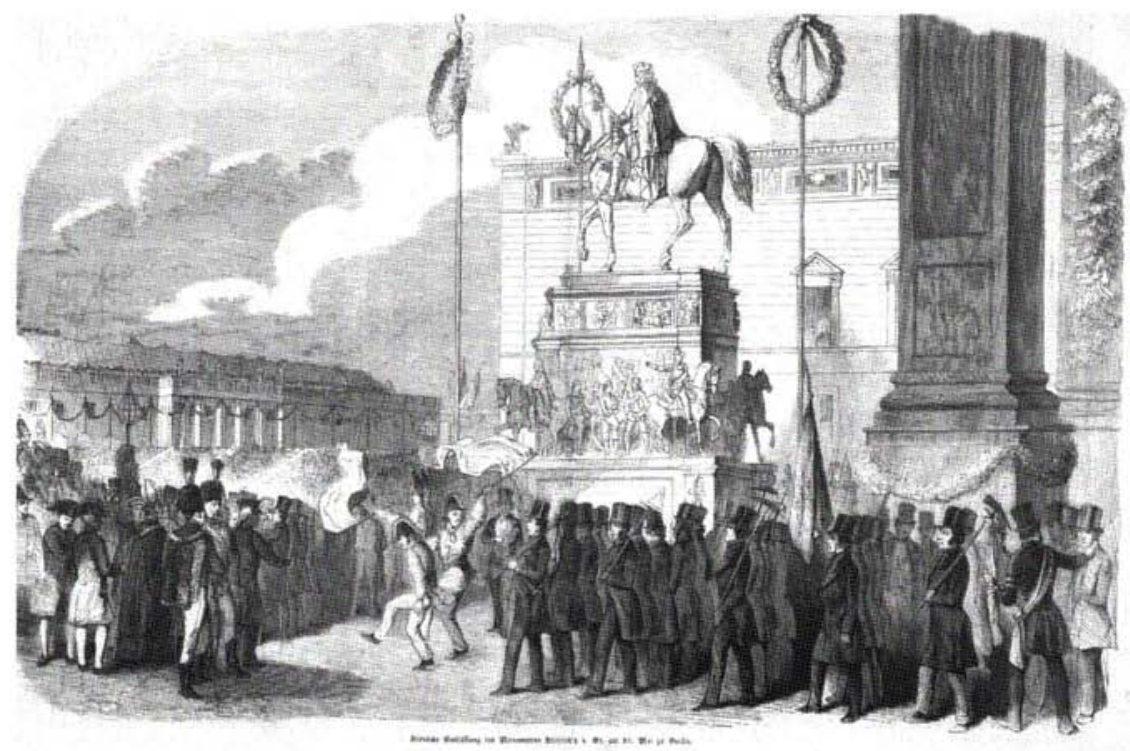

Abb. 3

Abb. 4

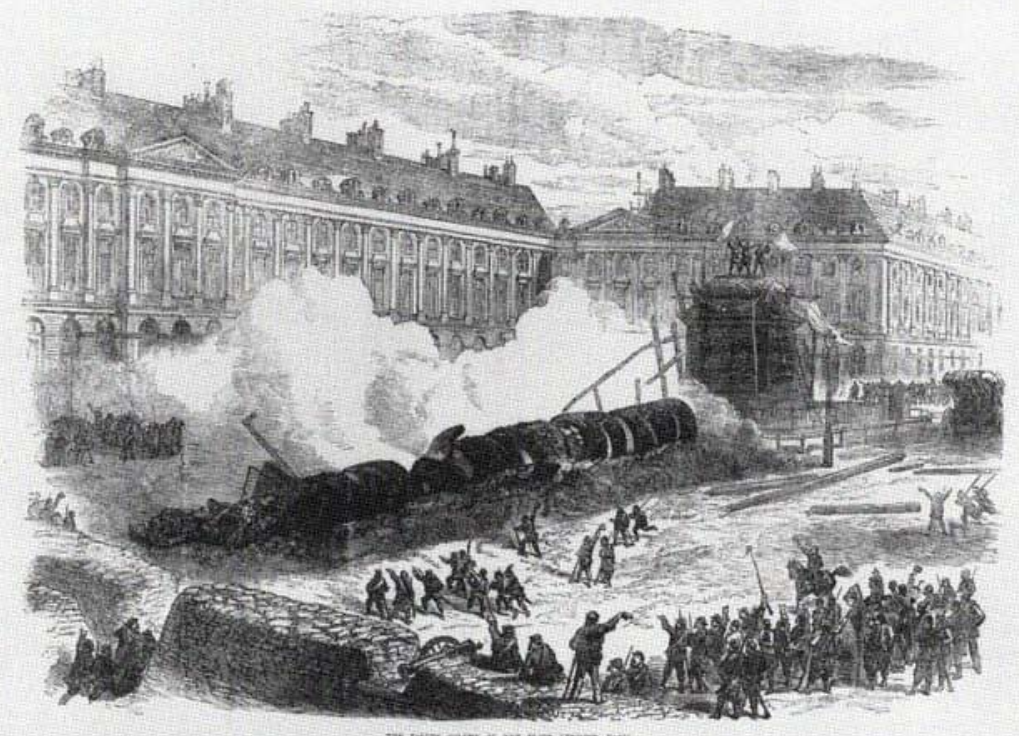




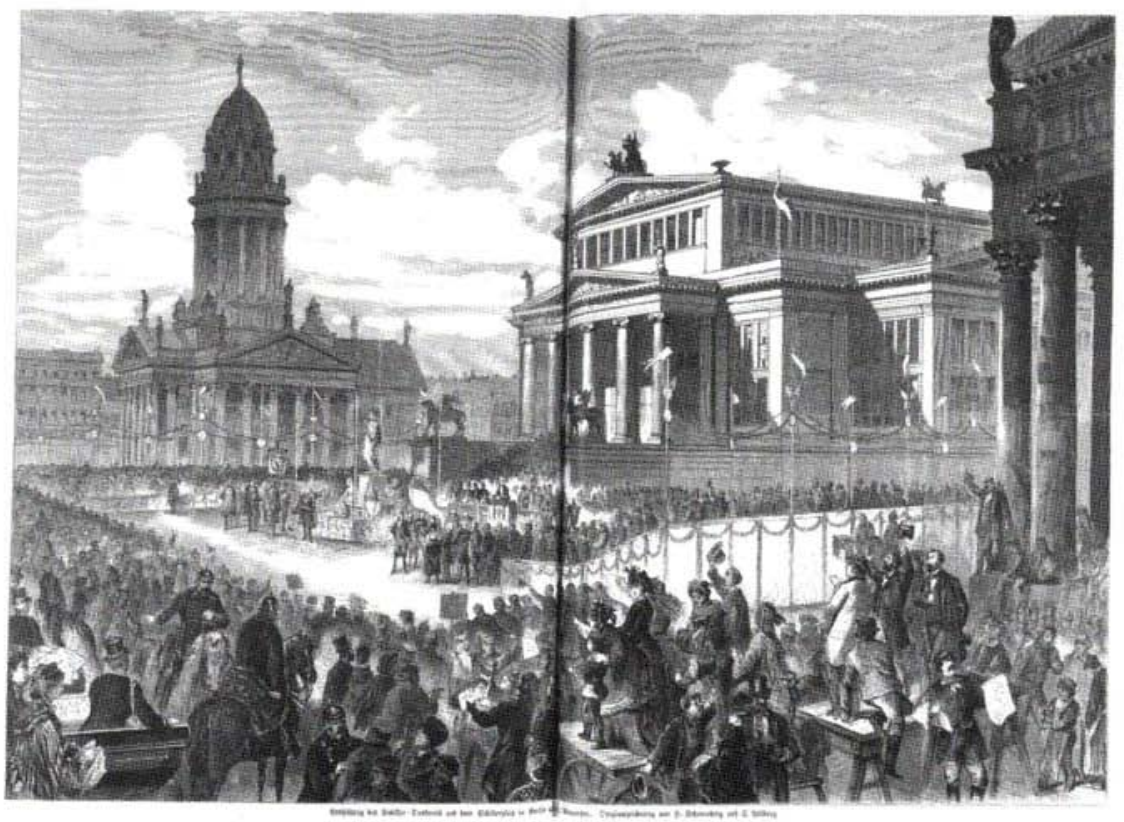

Abb. 5

Abb. 6

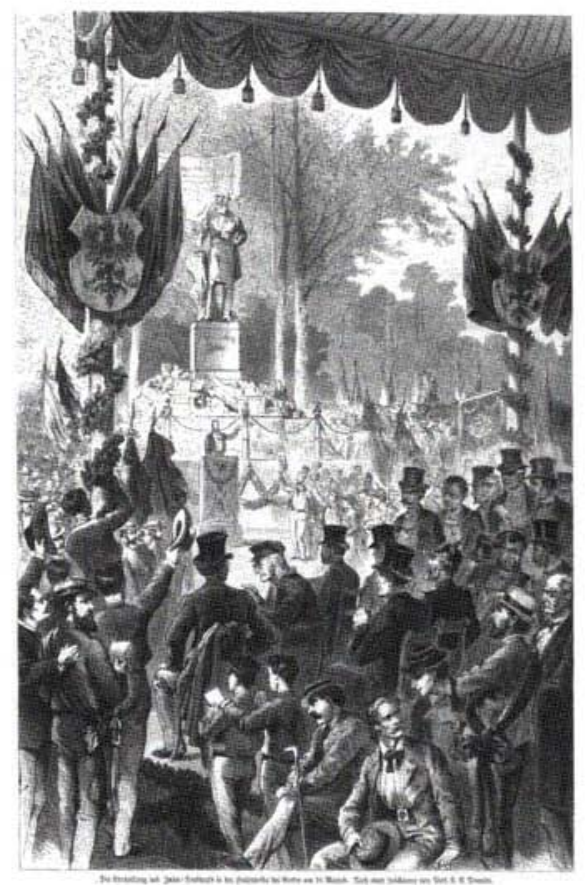




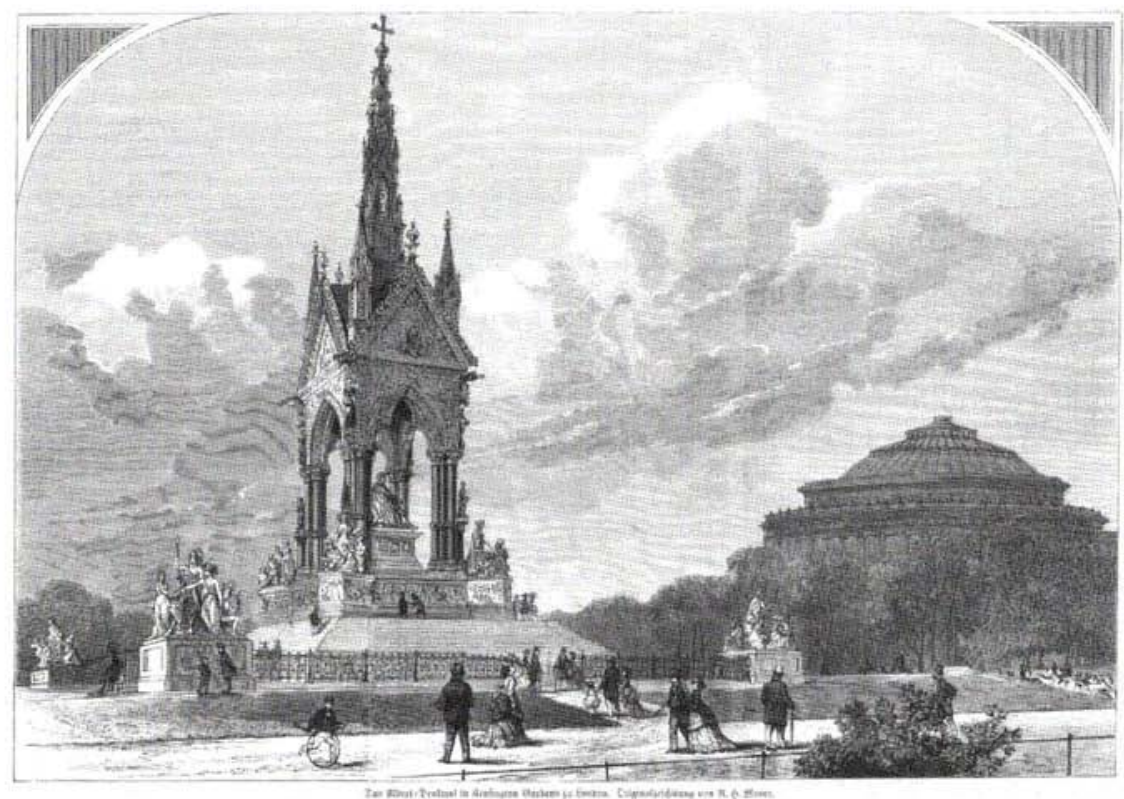

Abb. 7

Abb. 8

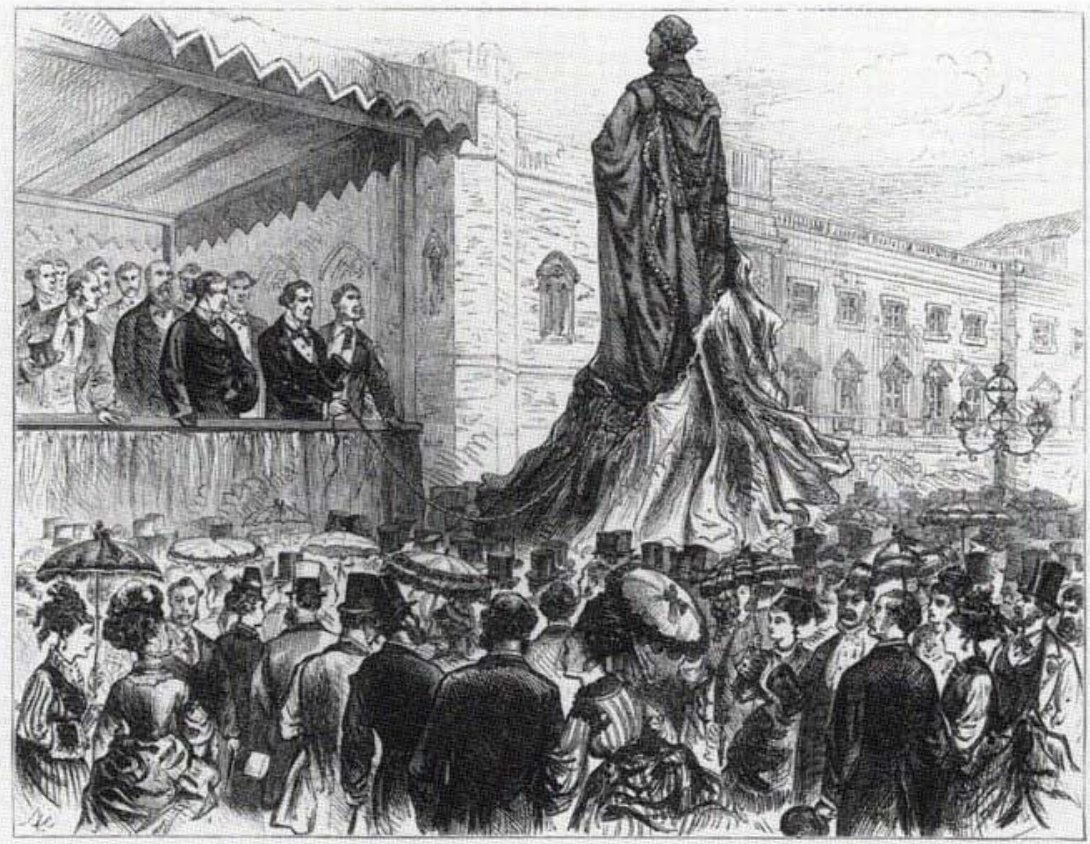




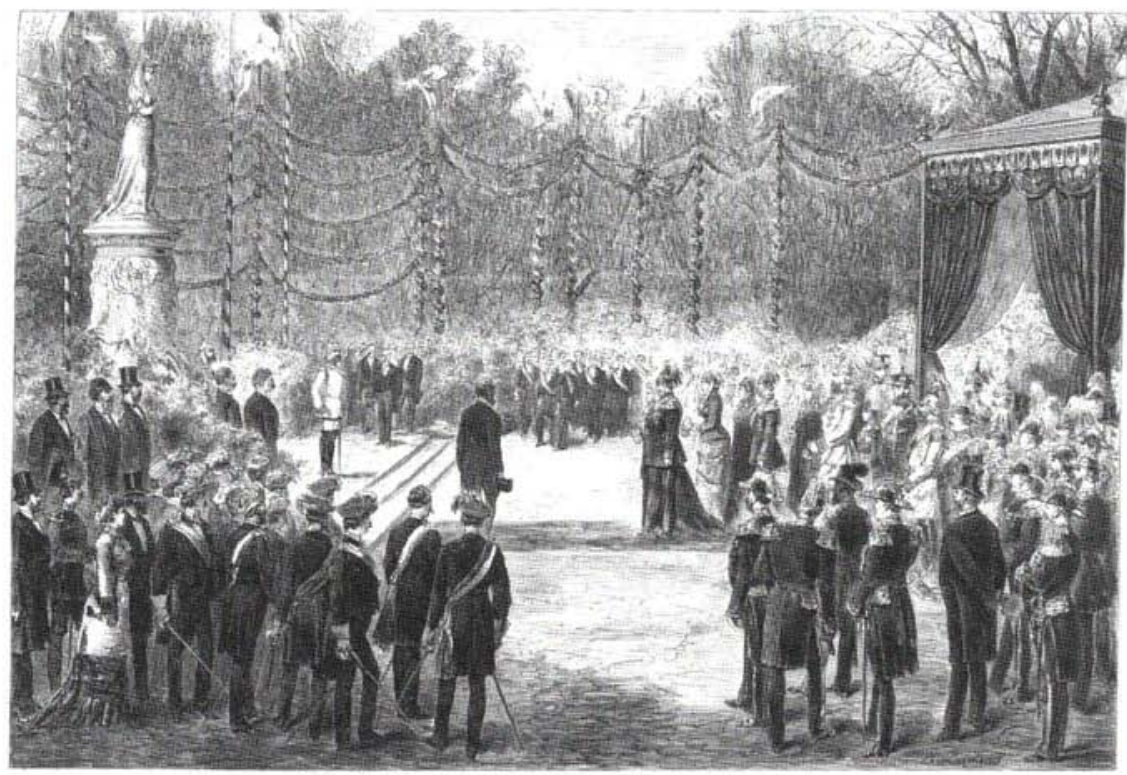

Abb. 9

\section{THE ILLUSTRATED LONDON NEWS}

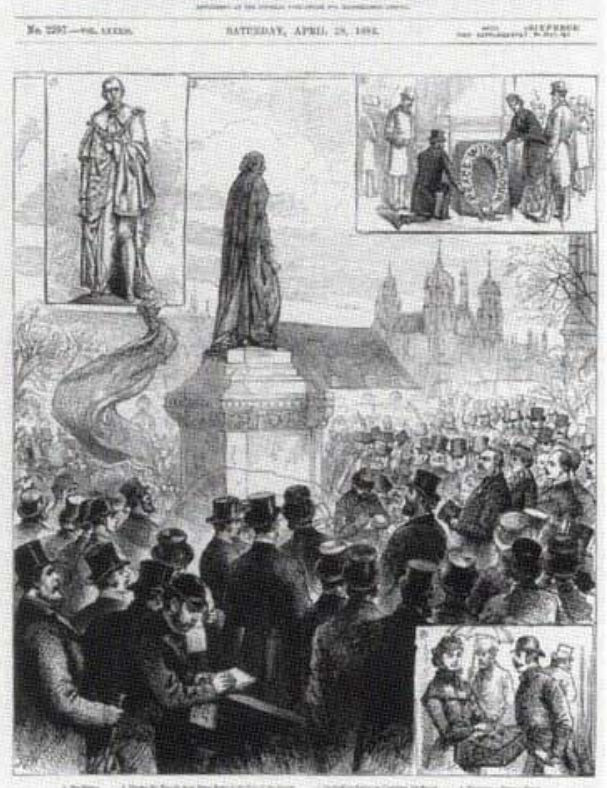

Abb. 10 


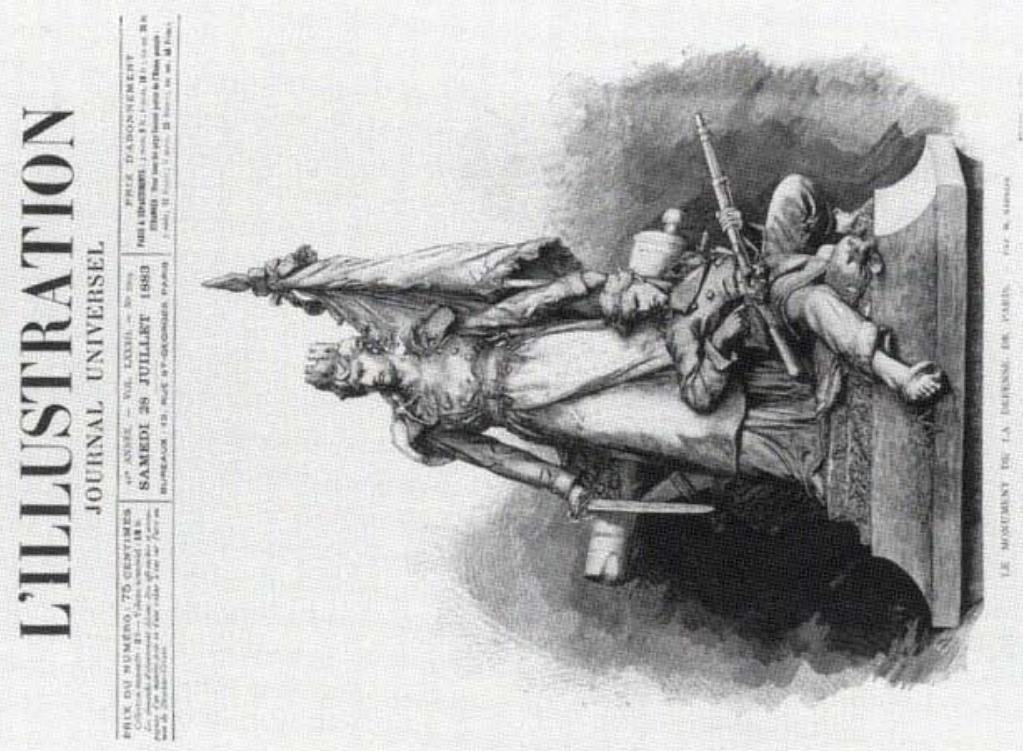

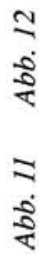

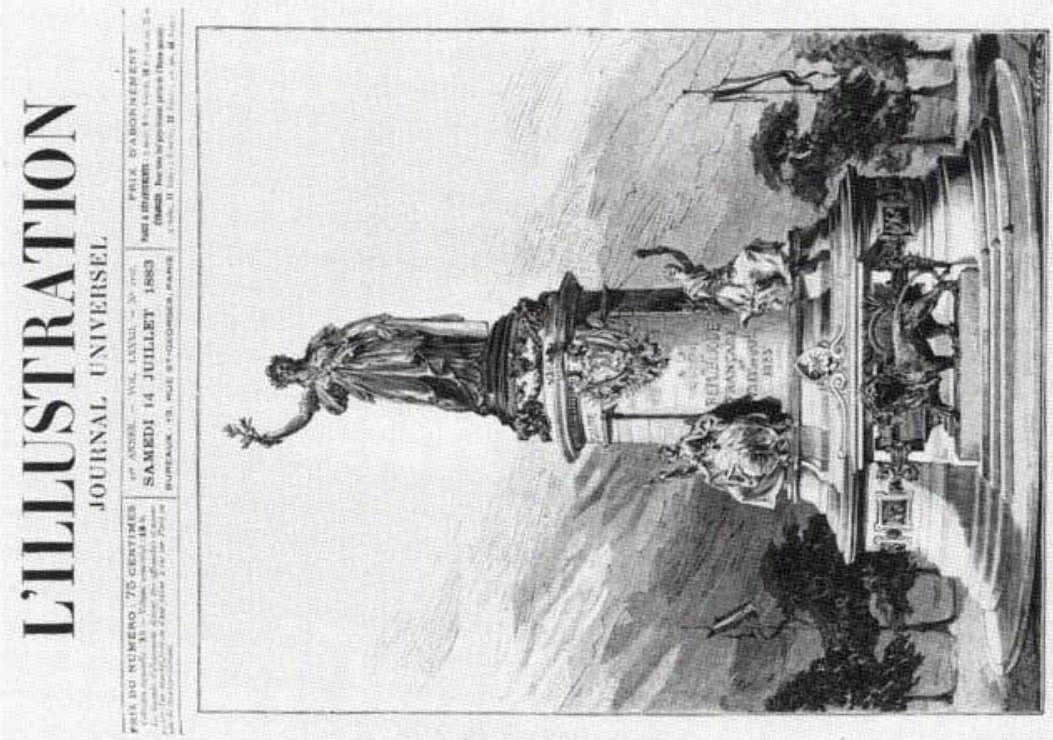




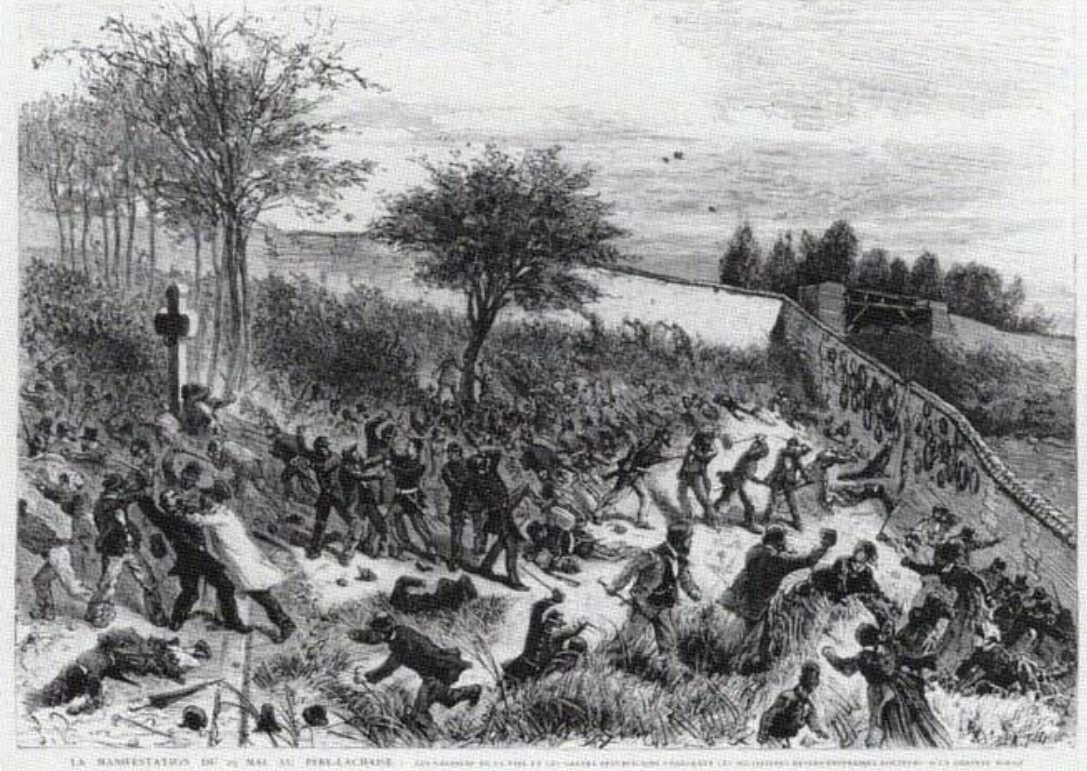

Abb. 13

Abb. 14

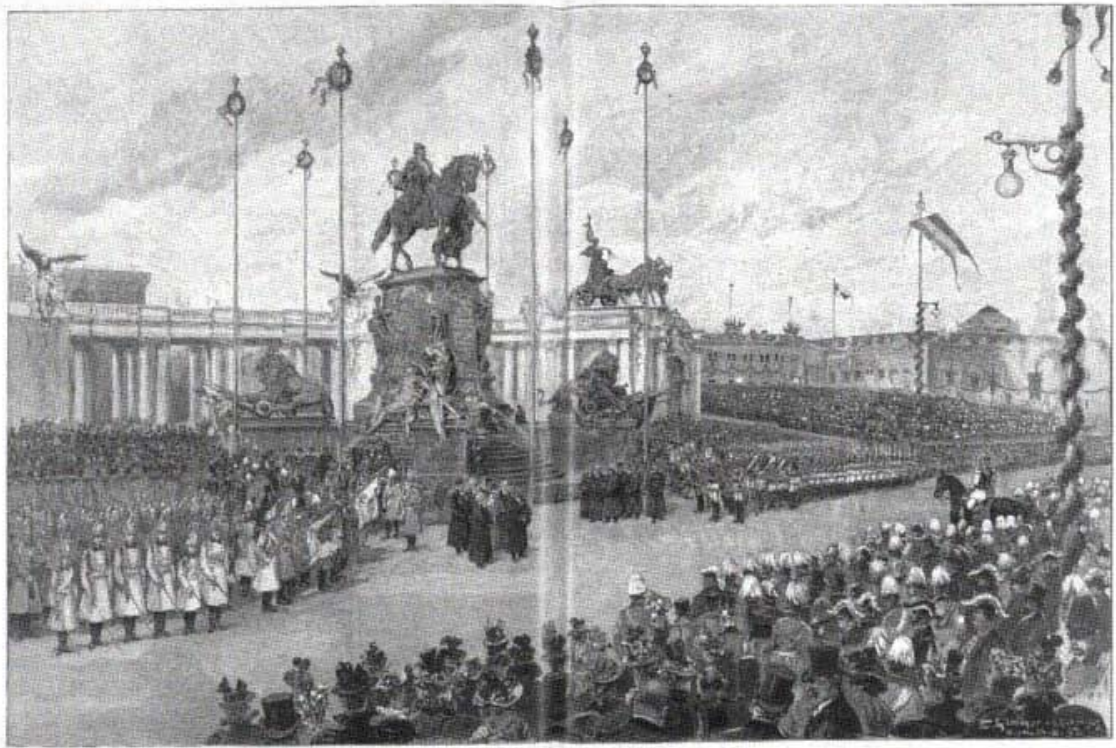




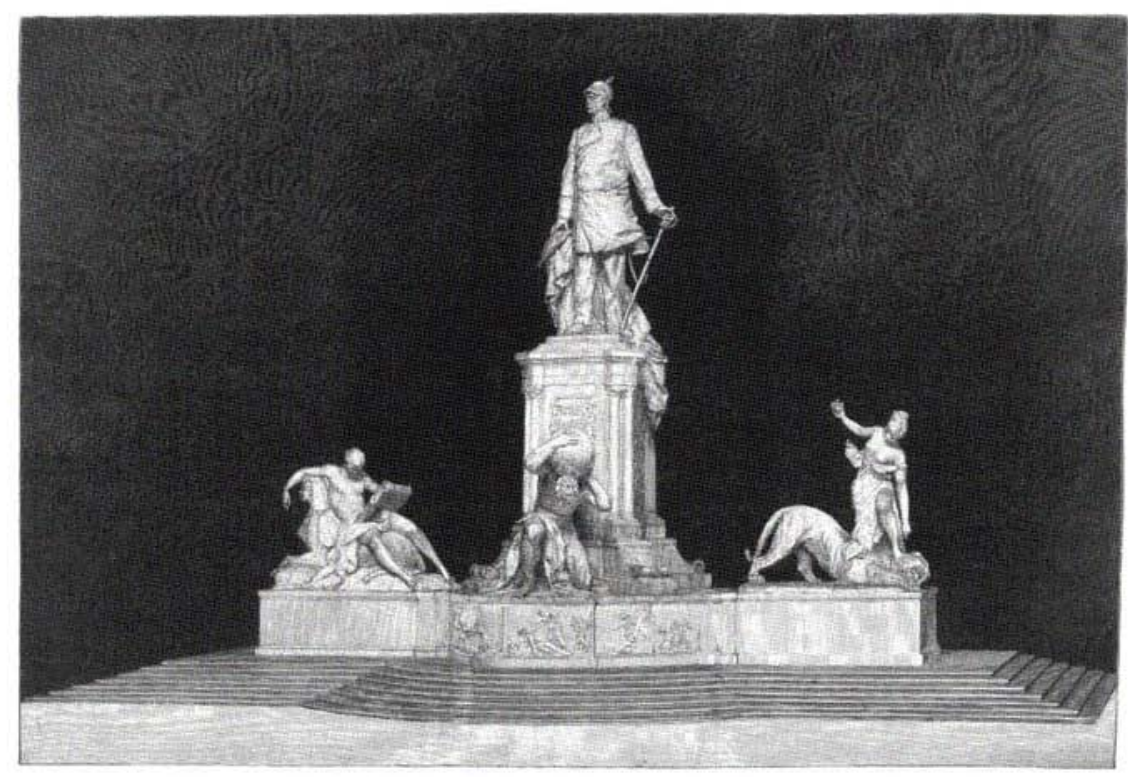

Abb. 15

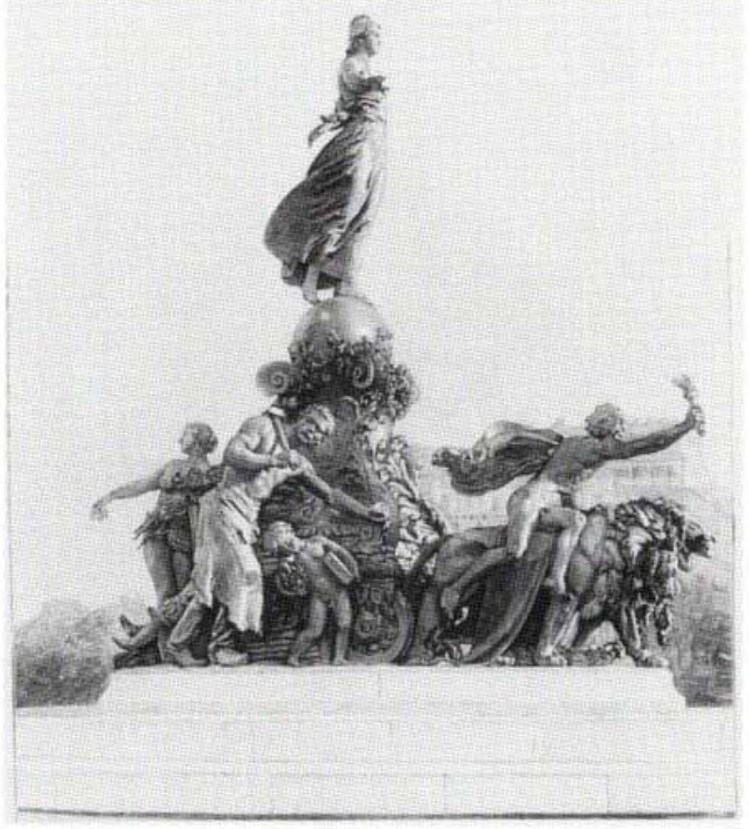

Abb. 16 